\title{
Permafrost Data Workshop 2020: Final Report
}

NSERC PermafrostNet

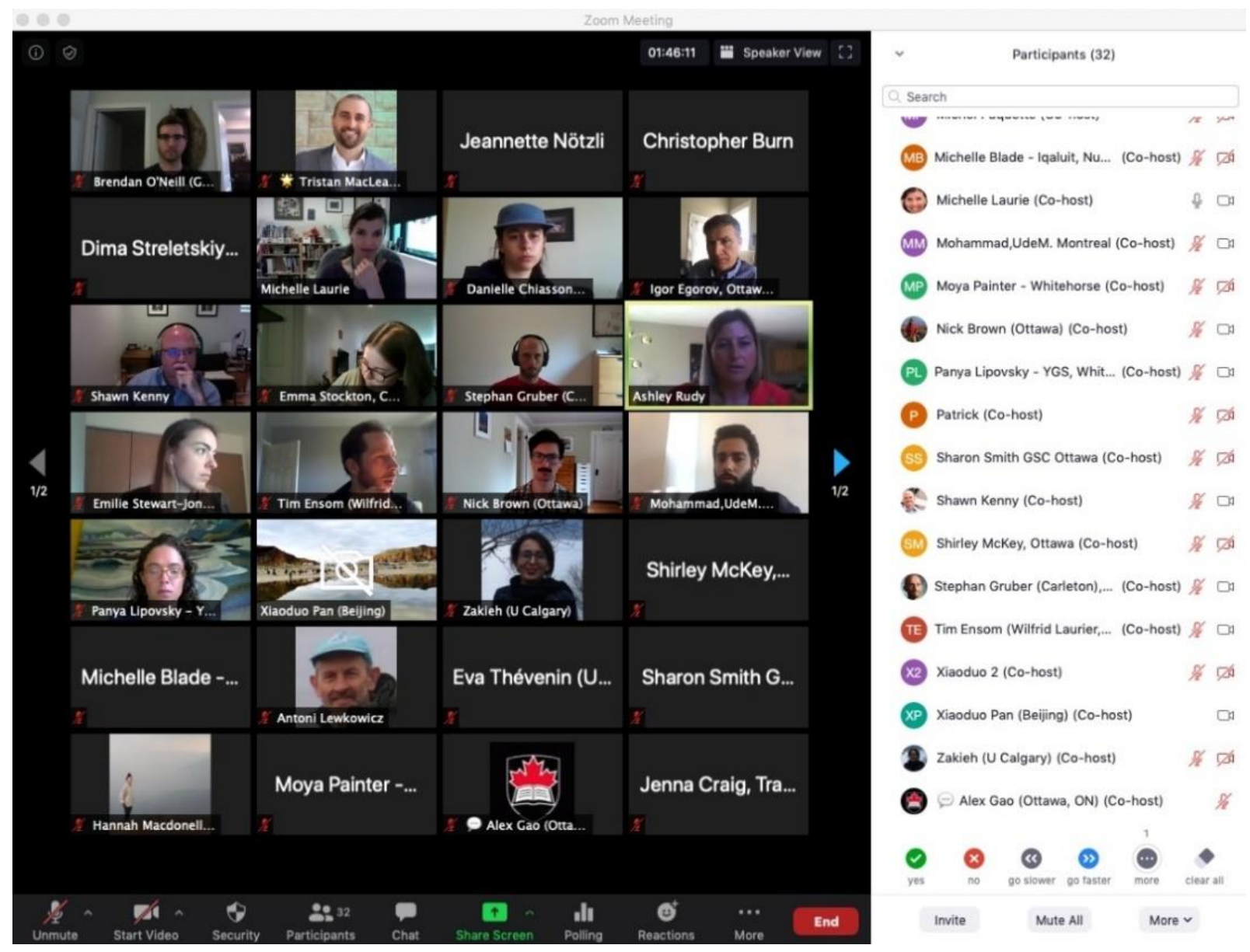

Citing this report:

Brown, N., Gruber, S., Pulsifer, P., Stewart-Jones, E. (2020) Permafrost Data Workshop Final Report. NSERC PermafrostNet. May 27-29, 2020: Ottawa, Canada. DOI: 10.22215/pn/10120001 . 


\section{Table of Contents}

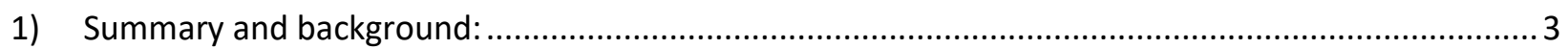

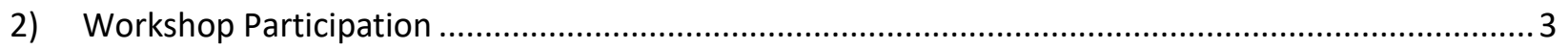

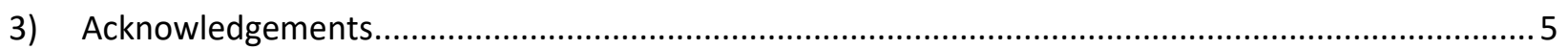

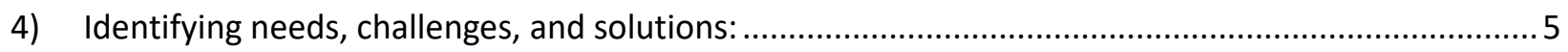

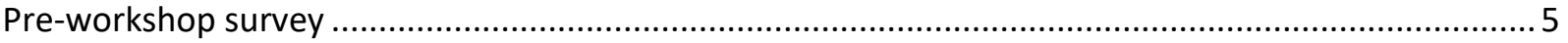

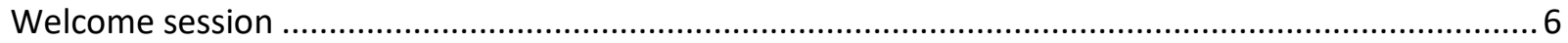

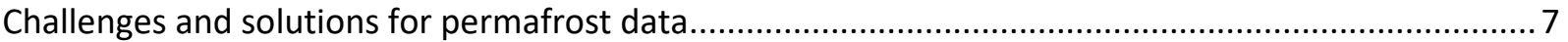

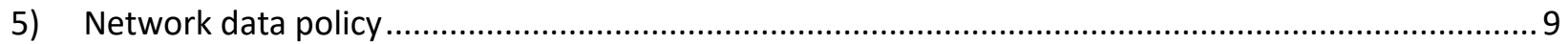

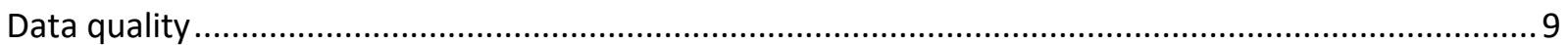

Open release

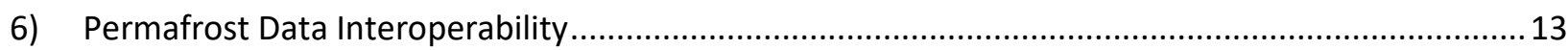

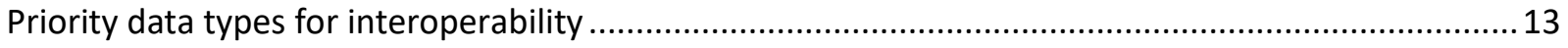

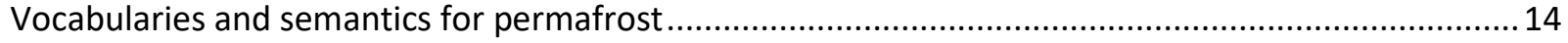

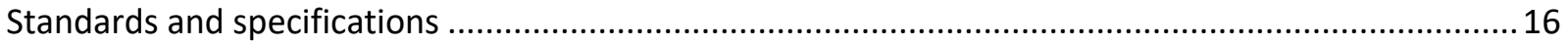

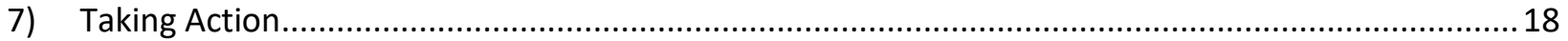

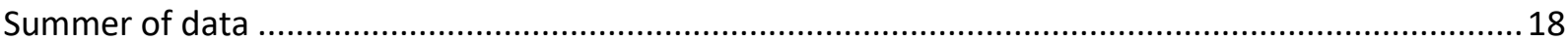

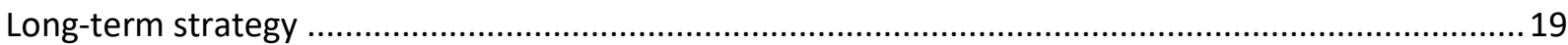

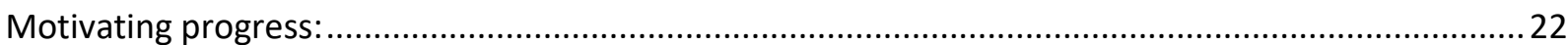

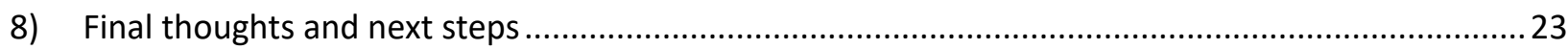

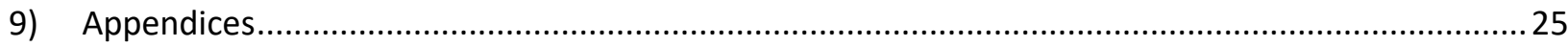

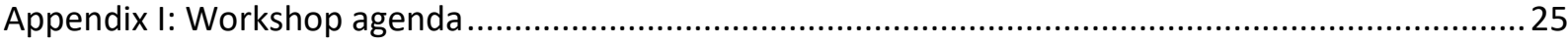

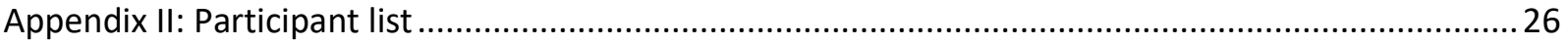

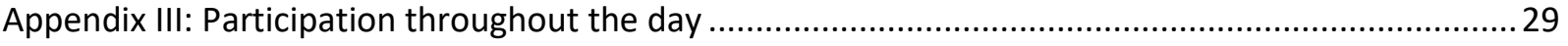

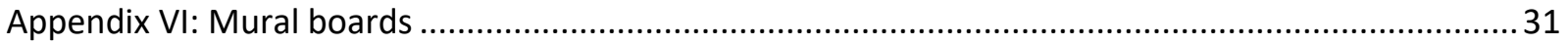




\section{1) Summary and background:}

The issue of permafrost data management, accessibility and harmonization has been a longstanding concern within the permafrost community. Previous permafrost workshops in $2013^{1}, 2017^{2}$ and $2018^{3}$ have highlighted the need to make permafrost data more accessible, and the need for support at all levels of the data life cycle including: quality control, access, publishing, referencing, interoperability and archiving. This workshop was designed to build on previous workshops by adding specificity and context to the data needs that have been established.

The main themes that emerged include:

- Capacity-building is needed at all levels: participants at all levels of permafrost data management highlighted that there are insufficient resources available for the significant task of gathering, cleaning, and disseminating permafrost data.

- Using existing tools and solutions is important to conserve resources, avoid the duplication of effort and ensure long-term sustainability.

- Access to standardized data and discoverability of data by remains a challenge.

- Continued communication will be essential to ensure that data systems are not developed in isolation.

\section{2) Workshop participation}

The workshop took place May 27-29, 2020 digitally via the Zoom communications platform. A total of 81 participants joined from five provinces, three territories and five different countries (Canada, USA, Switzerland, China and Japan). The event was originally planned to be an in-person meeting held in Ottawa but was moved to an online-only format, due travel restrictions during the COVID-19 pandemic. To compensate for this, the workshop made use of several digital collaboration platforms to recreate the in-person workshop experience as much as possible, including: Zoom, for videoconferencing; Mural, to display digital flipcharts and sticky-notes; ThoughtExchange, for collecting and ranking survey information; and Google Docs for collaboratively writing content. The workshop had strong participation across stakeholder groups including students, coinvestigators and network partners (Figure 1, Appendix III).

\footnotetext{
${ }^{1}$ Pan-Territorial Permafrost Workshop https://www.northernadaptation.ca/sites/default/files/pan-territorial permafrost workshop report 0.pdf

2 Towards a Canadian Permafrost Network: https://carleton.ca/permafrost/wp-content/uploads/WorkshopPermafrostNetworkOttawa2017 -Report.pdf

${ }^{3}$ Pan-Northern Meeting on Permafrost Hazard Mapping https://northernadaptation.ca/sites/default/files/summary report final compressed.pdf
} 


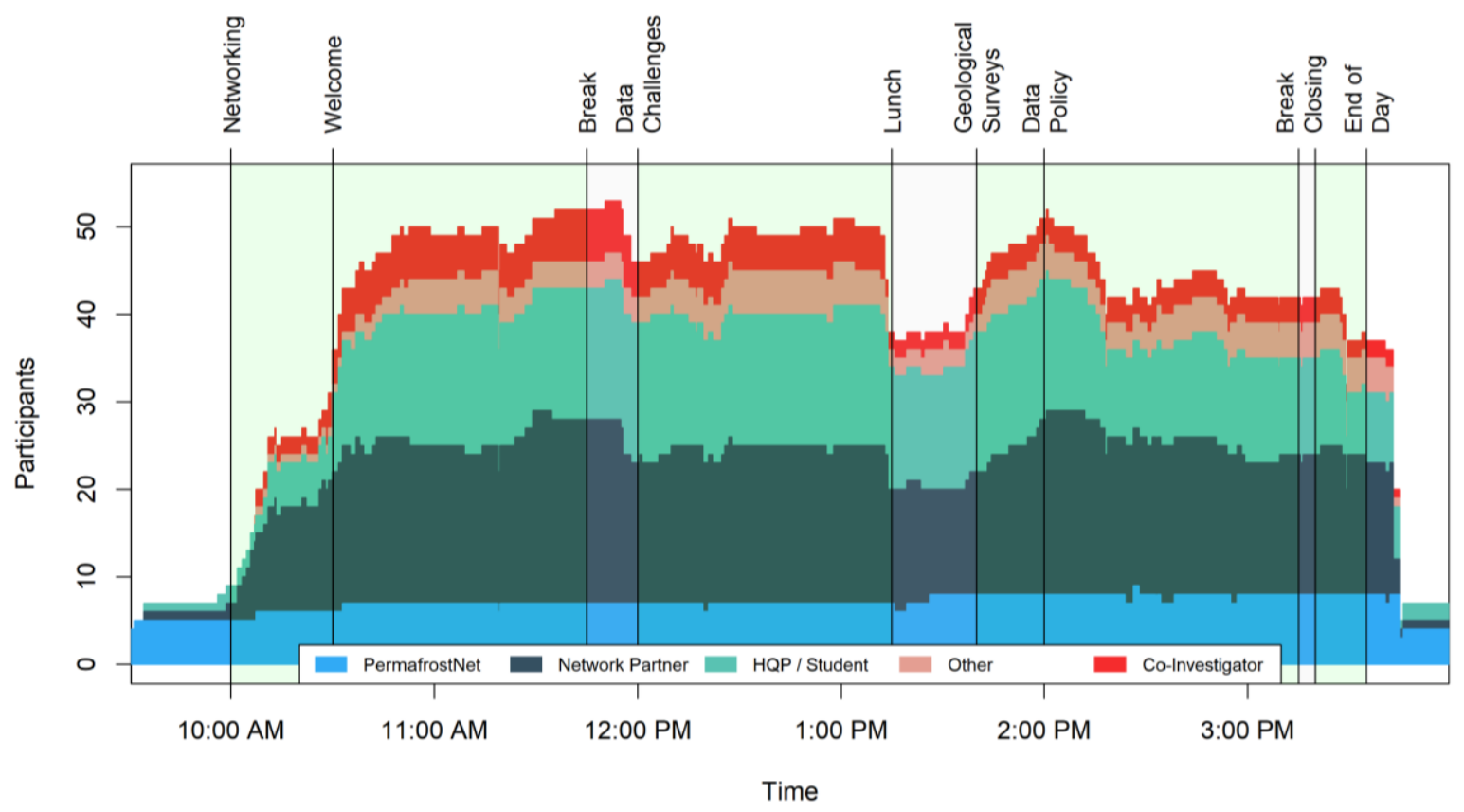

Figure 1: Participation on day 1 of the workshop (May 27, 2020) as determined by Zoom records and grouped by affiliation to PermafrostNet. Participation charts for all three days are shown in Appendix III.

The workshop featured presentations from national and territorial geological surveys (Geological Survey of Canada, NWT Geological Survey, Yukon Geological Survey) about their respective permafrost data and data systems. There were also presentations from individuals representing international permafrost or cryospheric data centres, including the Swiss Permafrost Monitoring Network (PERMOS), the Tibetan Plateau Data Centre (TPDC), and the Global Terrestrial Network for Permafrost (GTN-P). A presentation on semantics and the FAIR data principles provided participants with background knowledge to contribute on day 2. Copies of these presentations are available on the attendee's area of the workshop website $^{4}$

Overall, the workshop demonstrated strong northern involvement and commitment to permafrost data management (Figure 2, Appendix III). The workshop represented a diversity of views, approaches, and levels of prior knowledge. Although a multi-day workshop requires substantial effort, this broad engagement was effective in creating "buy-in" and support to move forward with a unified approach to permafrost data management at a national level. It also helped to create a shared vision and to elevate the technical and conceptual understanding of the broader permafrost community.

\footnotetext{
${ }^{4}$ https://www.permafrostnet.ca/resources/events/permafrost-data-workshop-attendees-area/
} 


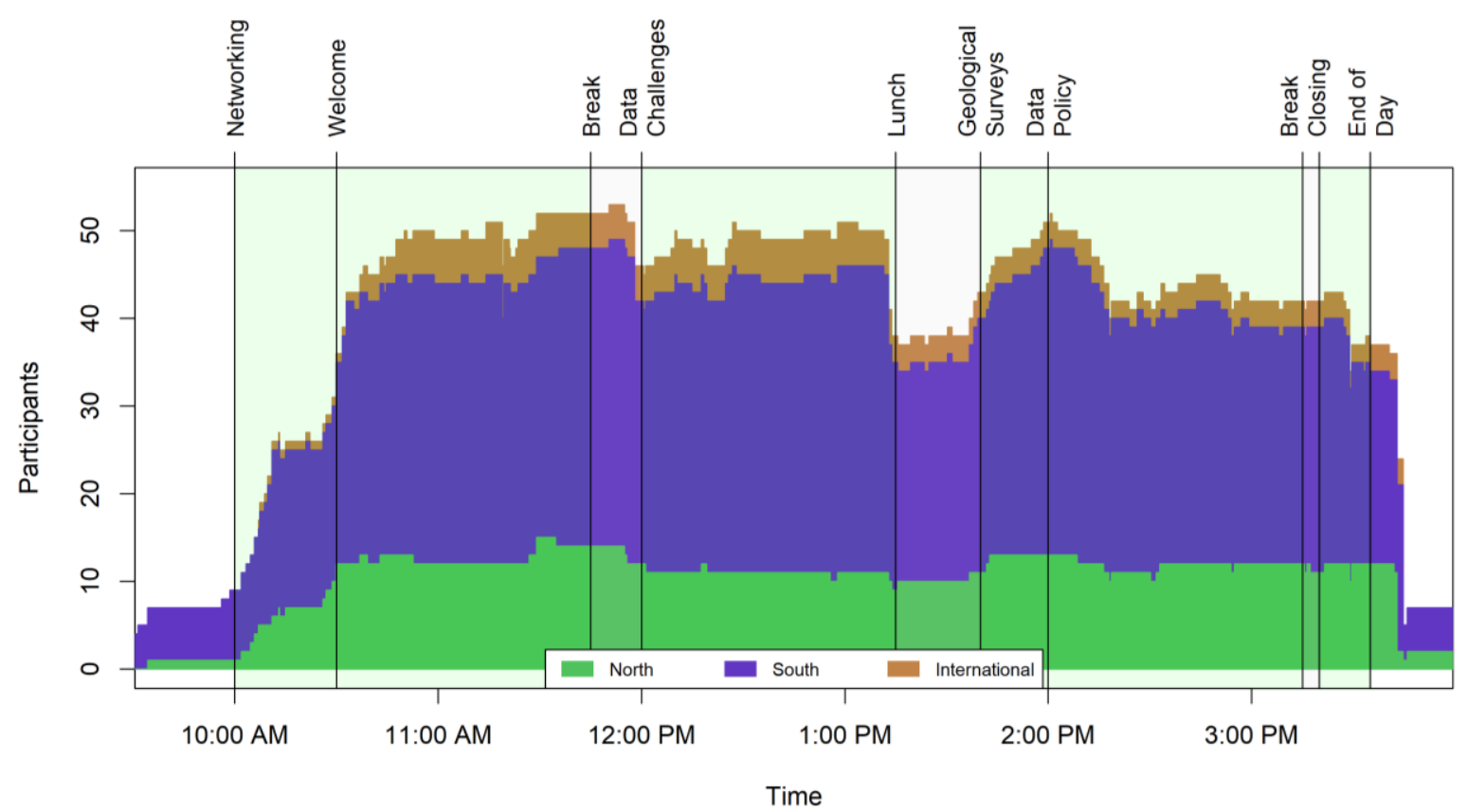

Figure 2 Participation on day 1 of the workshop (May 27, 2020) as determined by Zoom records and grouped by participant location.

\section{3) Acknowledgements}

This event would not have been possible without the help of the following people and organizations:

Michelle Laurie provided strategic process design and facilitation for the sessions. Tristan MacLean managed the technical aspects of running a virtual meeting to make sure things ran smoothly. Emilie Stewart-Jones, Tim Ensom, and Emma Stockton were rapporteurs for the sessions, taking notes and summarizing key ideas. Danielle Chiasson, Alex Gao, and Hannah Macdonnell helped moderate the chat.

Thanks also to everyone who volunteered their time to present or participate in a panel: Alex Bevington, Ashley Rudy, Boyan Brodaric, Dmitry Streletskiy, Étienne Godin, Jeanette Noetzli, Joe Melton, Matt Jones, Nick Brown, Panya Lipovsky, Peter Pulsifer, Sarah Brown, Stephan Gruber, and Xiaoduo Pan.

The workshop was put on with the help of the Canadian Consortium for Arctic Data Interoperability (CCADI) and Transport Canada. Finally, nothing would have been possible without the participation and enthusiasm of everyone who attended. A complete list of participants is included in Appendix II.

\section{4) Identifying needs, challenges, and solutions:}

\section{Pre-workshop survey}

In advance of the workshop, participants were invited to participate in a survey, which asked: Imagine its May 2021. What happened at this data workshop that was really important to you? What did we achieve or produce? Participants could then rank ideas generated by others. A total of 41 people responded to this question, generating 27 individual thoughts with 312 total ratings. These were themed into categories, the most popular of which was making permafrost data more interoperable. 


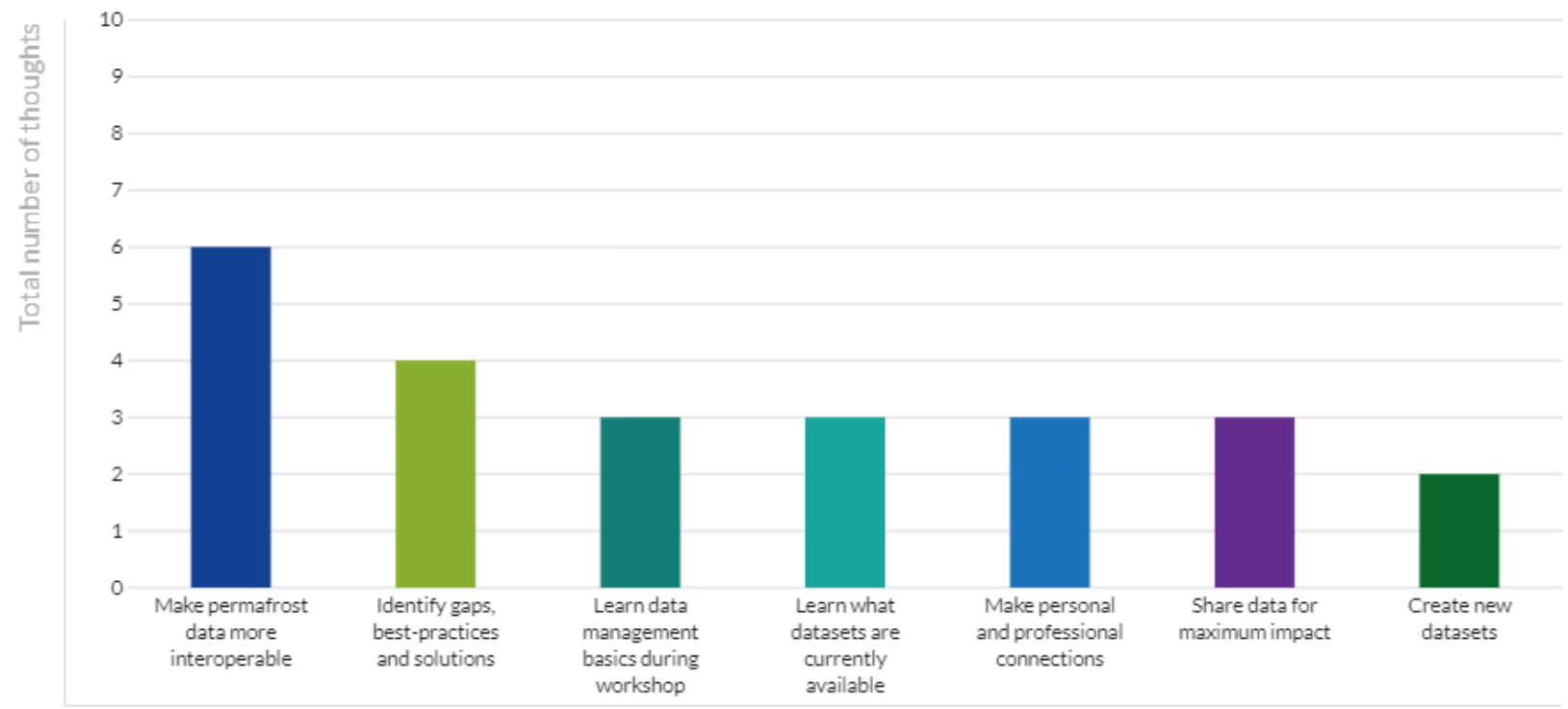

Figure 3: Results from pre-workshop survey grouped by theme.

\section{Welcome session}

The goal of the first morning session was to set the scene for the Permafrost Data Workshop and create a shared understanding of the workshop's purpose by discussion of shared challenges and opportunities. The morning began with a panel discussion to answer the question: "In your experience what's the biggest challenge you face in accessing, using or sharing permafrost data"

Table 1: Panellists for the introductory session

\begin{tabular}{|l|l|}
\hline Ashley Rudy & NWT Geological Survey \\
\hline Sarah Brown & NWT Association of Communities \\
\hline Joe Melton & Environment and Climate Change Canada \\
\hline Alex Bevington & $\begin{array}{l}\text { BC Ministry of Forests, Lands and Natural Resource Operations and Rural } \\
\text { Development }\end{array}$ \\
\hline
\end{tabular}

Throughout the discussion of challenges to accessing, using, and sharing permafrost data, a number of recurring themes emerged:

1. Data standardization. How should we go about creating data standards and what are the important considerations? How should I (as a data collector) format my data for others? How do we harmonize data from multiple sources?

2. Limited resources. Cleaning and formatting data require a great deal of time, which is often in short supply both for researchers and even organizations responsible for data management

3. Data sharing. How do we raise awareness and get buy-in across the community? How to create incentive for sharing data?

4. Sustainability. How do we sustain a permafrost database or data repository in the long run?

Some specific challenges unique to different user groups were also brought up (Table 2) 


\begin{tabular}{|l|l|}
\hline Who & Challenge or need \\
\hline Government & $\begin{array}{l}\text { Standardizing data (from multiple sources) so that it is useable requires time, } \\
\text { and resources are limited for this task. }\end{array}$ \\
\hline Government & It is difficult to find permafrost data within government. \\
\hline Modeler & I need access to large amounts of data from a single standardized source. \\
\hline Modeler & $\begin{array}{l}\text { Variability in permafrost metadata makes it hard to search. } \\
\text { We need standardized metadata. }\end{array}$ \\
\hline Communities & Community members and workers do not know where to find permafrost data. \\
\hline $\begin{array}{l}\text { Field scientist and } \\
\text { data user }\end{array}$ & $\begin{array}{l}\text { Data (metadata) changes over time, so we need a way of accounting for } \\
\text { environmental change over time (rocks falling from rock wall where a sensor is } \\
\text { installed). }\end{array}$ \\
\hline Scientist & It is important to preserve original data (raw data and metadata). \\
\hline All & Different levels of data processing are required for different user groups. \\
\hline
\end{tabular}

\section{Challenges and solutions for permafrost data}

The next session was designed to identify shared problems within the permafrost community, leverage network connections to help identify what is needed to help with the data creation process, and to identify use cases for data. After organizing into small groups, participants posted their challenges, solutions and ideas using different coloured sticky-notes on a digital flipchart (Figure 4, Appendix IV). This session provided a forum for participants to share experience and demonstrated the value of operating as part of a network.

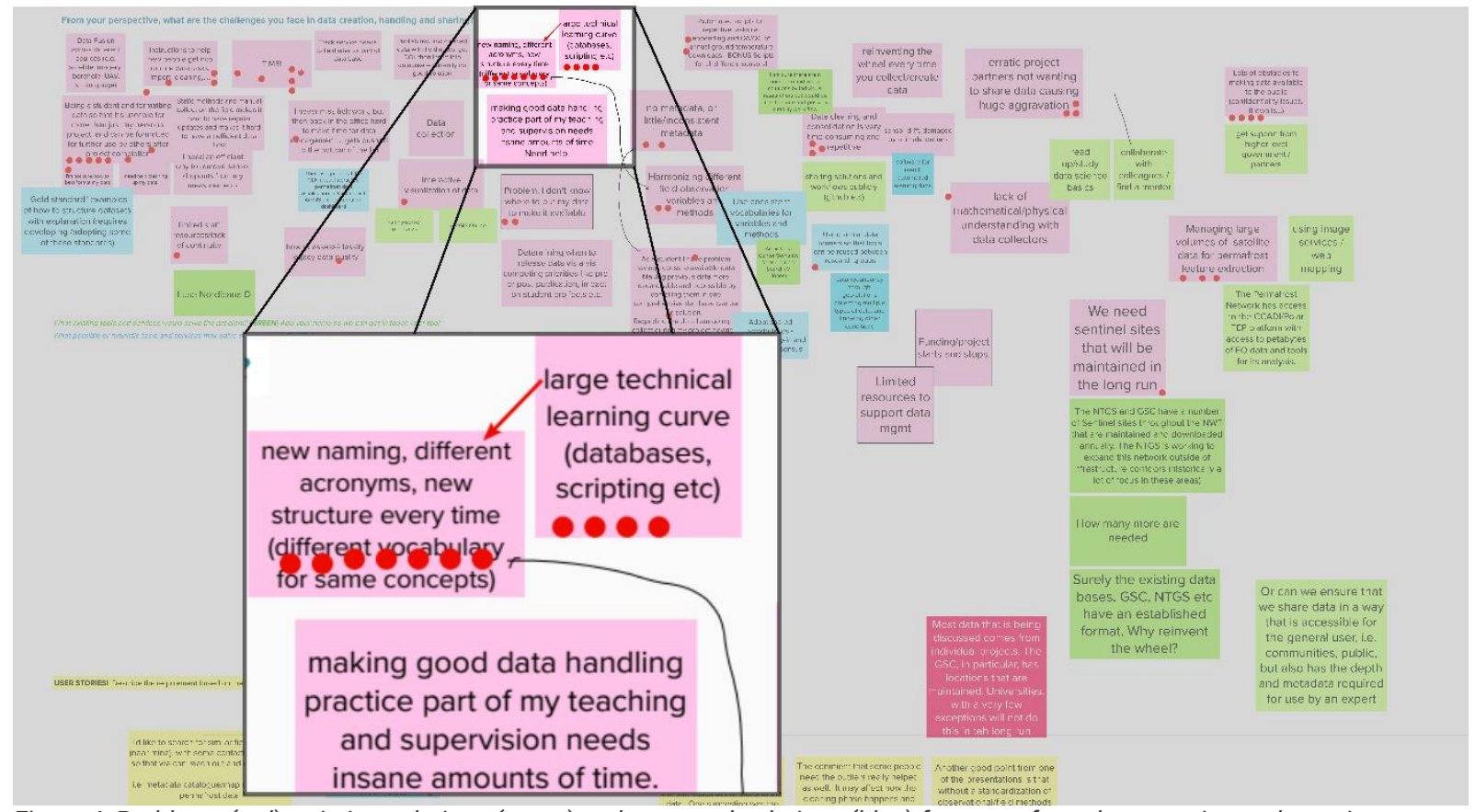

Figure 4: Problems (red), existing solutions (green) and proposed solutions (blue) for permafrost data creation and curation. Participants added red 'stickers' to indicate priority items. Zoomed detail-view shown for clarity. A full-resolution version is available in Appendix IV. 
Throughout the discussion (verbal and written) on the problems and challenges with data creation and access, a number of recurring themes surfaced:

- Limited resources: both time and funding

- Data inconsistencies

- Need for instruction on data management

- A number of general barriers to data sharing

Highest among participant's challenges was finding the time for data management. For governments, the trouble manifests as a lack of continuity in data management projects due to inconsistent funding. A proposed solution to this problem was sharing data cleaning and formatting tools and workflows such as automated scripts. Developing universal software for these tasks would be the longer-term goal. In both cases, making the data more homogenous and/or interoperable will be an important first step so that the automation of certain workflows is feasible.

Inconsistencies in vocabularies, data collection methods, data structure, and metadata remain major obstacles to data interoperability. Two solutions were suggested: (1) Adopting shared vocabularies with community buy-in and scientific consensus and (2) developing standards and guidelines for cleaning, formatting, and structuring data within the network.

Although solution (2) would provide guidance to network students collecting and formatting their data, the large technical learning curve to data management tasks such as scripting and working with databases still requires a solution.

Finally, problems around data sharing were wide-ranging, from questions about how and where to share data to concerns around releasing data. Solutions to the former issue were to create a separate data repository for the network or to work with existing repositories to provide storage for datasets and/or to generate DOIs. Because the permafrost community may have needs that are not currently met by any existing repositories, (such as access to data as a OGC WMS service), a hybrid approach may be desirable in which some data are kept on PermafrostNet servers. If any data are held exclusively by PermafrostNet, they will likely need to be transferred to a more stable location at the conclusion of network funding.

Table 3: Specific scenarios and needs

\begin{tabular}{|c|c|}
\hline Who & Scenario or need \\
\hline Field researcher & $\begin{array}{l}\text { "I'd like to search for similar field locations (near mine), with some contact } \\
\text { information so that we can reach out and collaborate. i.e. metadata } \\
\text { catalogue/map of Canadian permafrost data." }\end{array}$ \\
\hline $\begin{array}{l}\text { Decision makers, consultants, } \\
\text { and less technical users }\end{array}$ & "Provide higher level summary data [...]" \\
\hline Data interface developer & "I need to understand the use cases of the users of the data" \\
\hline Researcher & "I need 'raw' data for certain studies" \\
\hline Field researcher & "Track service needs to field sites as part of database" \\
\hline Field researcher & $\begin{array}{l}\text { "I need an efficient way to remove sensor dropouts from my } \\
\text { measurements" }\end{array}$ \\
\hline Field researcher & $\begin{array}{l}\text { "Provide a location to host our raw data quickly at the end of the field } \\
\text { season, then we can take our time to clean/update" }\end{array}$ \\
\hline
\end{tabular}


A short discussion on how these challenges can be met in the short- and long-term elicited responses from two participants, however no specific consensus was achieved.

\begin{tabular}{|l|l|l|}
\hline Timeframe & Participant 1 & Participant 2 \\
\hline Short term & $\begin{array}{l}\text { Developing a web map of available } \\
\text { permafrost data with metadata }\end{array}$ & $\begin{array}{l}\text { - Developing processing tools for the } \\
\text { primary data types: ground temperature } \\
\text { and geotechnical data } \\
\text { - Making the other data types available } \\
\text { without standardization }\end{array}$ \\
\hline Long term & $\begin{array}{l}\text { Creating a universal set of tools for } \\
\text { automation of data processing }\end{array}$ & \\
\hline
\end{tabular}

\section{5) Network data policy}

This session focused on two elements of the NSERC PermafrostNet data policy that were flagged during community consultation in winter 2020: (1) the adoption of a data quality management plan to ensure the network is a trusted source for data and (2) the issues of open data release. Both topics also have implications beyond the network for the long-term needs to support permafrost data management in Canada.

\section{Data quality}

The first part of the session dealt with discussions of what is needed for data quality management within the network and beyond. This could have implications for professionals who use network data. In other data policies considered, data quality was either not mentioned (GTN-P, NSIDC), explicitly not guaranteed (Nordicana-D, GWF, ArcticNet) delegated to the researchers submitting the data (GWF, ArcticNet), or quality checked by the organization accepting the data (PERMOS).

Although the session began with a focus on establishing data quality criteria, the general agreement by the end was that making well documented data available can be more valuable than establishing a formal quality control system. In short, data "quality" is context-specific and is difficult to define for all user groups.

Participants were asked to brainstorm individually and in small groups, a 'dream list' of all the elements in an ideal data quality management plan for permafrost data. They returned to plenary and took part in a survey to identify the minimum specifications for this plan by posting items from their dream list and rating the ideas that others suggested.

Table 4: Examples of data quality elements grouped into themes

\begin{tabular}{|l|l|}
\hline Theme & Participant suggestions for a data quality management plan \\
\hline \multirow{3}{*}{ Metadata: General } & $\begin{array}{l}\bullet \text { Metadata (location, provenance, uncertainty, etc) is required for } \\
\text { datasets and data elements (e.g. observations) }\end{array}$ \\
& $\begin{array}{l}\text { - Inclusion of metadata } \\
\text { - Clear Metadata Standards }\end{array}$ \\
\hline
\end{tabular}




\begin{tabular}{|l|l|}
\hline $\begin{array}{l}\text { Metadata: Data } \\
\text { quality levels or } \\
\text { lineage }\end{array}$ & $\begin{array}{l}\text { - After data processing has been done, outline what steps have taken } \\
\text { - Include data provenance and methodology }\end{array}$ \\
\hline $\begin{array}{l}\text { Metadata: Site } \\
\text { Conditions }\end{array}$ & $\begin{array}{l}\text { - Rank data quality (letter grade) } \\
\text { - "Levels" of data cleaning (level 0 = raw, level 1= cleaned) }\end{array}$ \\
\hline $\begin{array}{l}\text { - Qualitative comments: Notes in the data on site changes over time. } \\
\text { Visualization Tools }\end{array}$ & $\begin{array}{l}\text { - Automated filters: Thresholds, outliers, etc. } \\
\text { - Visualization: Easy visualization of data will help find problems in the }\end{array}$ \\
\hline Raw Data & - Tool(s) or methods to detect gross or "out of range" errors \\
\hline Long-term & $\begin{array}{l}\text { - Raw data: Keep raw data in database } \\
\text { - Raw data is good so that processing can be repeated }\end{array}$ \\
\hline considerations & $\begin{array}{l}\text { - Imperfect data can be useful } \\
\text { - Lonsistent and simple system that can be maintained over the long term }\end{array}$ \\
\hline
\end{tabular}

The most common dream list suggestions were thematically related to a need for metadata, software or visualizations to help perform quality control, and the preservation of raw data. In addition to the general need for metadata, two specific categories of metadata emerged as common recommendations: descriptions of site conditions, and a description of the processing steps or processing levels. Tools for data checking were more popular in the dream list than in the final list of minimum specifications. 


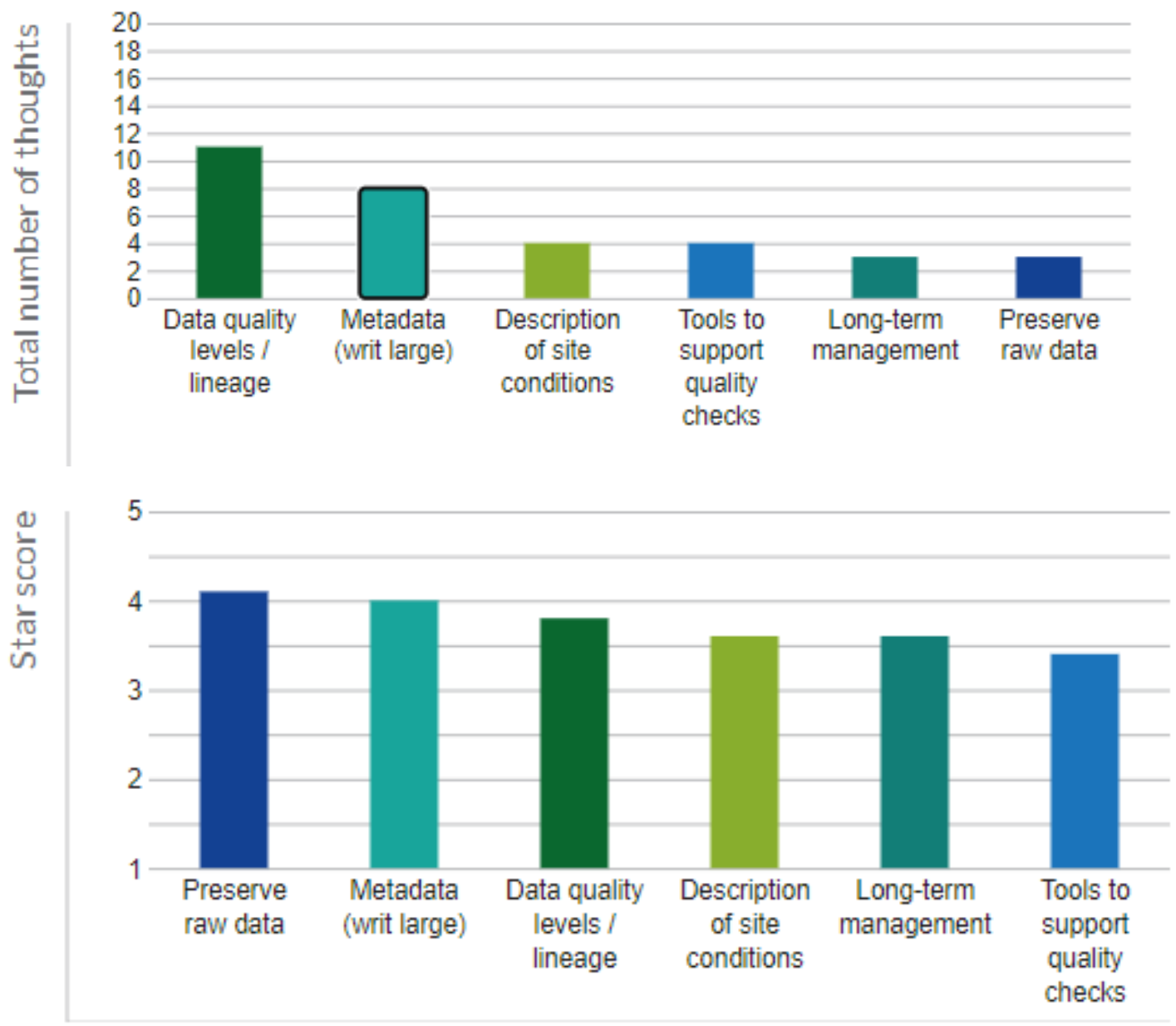

Figure 5: Total number of thoughts in each theme (top) and ranking of data quality elements as essential chosen by workshop participants (bottom).

Other thoughts that did not fall into a clear theme included having a feedback mechanism for users to report issues with the data, and including a disclaimer with the data to reduce any liability. Some of the un-themed thoughts were more closely related to broader principles of data interoperability than quality per se, such as the "use of FAIR principles", having "open data, not private data" and requiring "Lots of documentation to make sure that data quality management is consistent".

The results of this session suggest that core elements of a data quality management plan require having the appropriate metadata to judge whether data are fit for a specific purpose and having access to the raw data. Software tools are important to support quality control, and are desired by the community, but are less essential for ensuring that network data can be trusted. 


\section{Open release}

One of the aims of releasing data openly is to make it useful to people outside of the network. To explore this issue from another perspective, a technique called TRIZ was used to flip the question around; participants were asked to identify all the possible ways to achieve the most undesirable outcome, namely: "What can we do to ensure that data generated by the network is not findable, accessible or reusable by people outside the network?". The TRIZ method is thought to allow groups to challenge conventional practices and discuss topics that are difficult to discuss.

Participants created a list of possible behaviours that would lead to this undesirable outcome, then added stars next to things that they do or that they have experienced in any way, shape, or form. The most commonly reported behaviours fell under the themes of intentionally restricting access, publishing data late and systemic policy issues.

Table 5: Behaviours that the community can undertake to achieve the undesirable outcome of making sure data generated by the network is not findable, accessible or reusable by people outside the network. Higher numbers of stars are related to behaviours that are more commonly experienced or impede the reused of data most strongly.

\begin{tabular}{|l|l|c|}
\hline Theme & Participant Examples & Stars \\
\hline $\begin{array}{l}\text { Intentionally restrict } \\
\text { access }\end{array}$ & $\begin{array}{l}\text { - Keep data offline } \\
\text { - Password-protected } \\
\text { - Unwilling to share data }\end{array}$ & $\mathbf{2 4}$ \\
\hline Publish data late & $\begin{array}{l}\text { - Take years to release data } \\
\text { - Not sharing data until after end of research project, PhD, MSc, ... }\end{array}$ & $\mathbf{2 3}$ \\
\hline Systemic issues & $\begin{array}{l}\text { - Require multiple levels of approvals to release data } \\
\text { - Have 1 central gatekeeper }\end{array}$ & $\mathbf{2 0}$ \\
\hline $\begin{array}{l}\text { Inappropriate } \\
\text { format }\end{array}$ & $\begin{array}{l}\text { - Share data in a proprietary format that requires paid software } \\
\text { - Use Excel formatting to store data (i.e. blue = data from sensor 1) }\end{array}$ & $\mathbf{1 4}$ \\
\hline $\begin{array}{l}\text { Don't allocate time } \\
\text { or resources to data }\end{array}$ & $\begin{array}{l}\text { - Ignore data requests } \\
\text { - No manager of legacy datasets }\end{array}$ & $\mathbf{1 3}$ \\
\hline $\begin{array}{l}\text { Inadequate } \\
\text { metadata }\end{array}$ & $\begin{array}{l}\text { - Raw data with calibration missing } \\
\text { - No metadata }\end{array}$ & $\mathbf{1 3}$ \\
\hline Legal restrictions & $\begin{array}{l}\text { - Require a signed agreement to ensure liability } \\
\text { - Require confidentiality clauses }\end{array}$ & $\mathbf{8}$ \\
\hline $\begin{array}{l}\text { Don't release raw } \\
\text { data }\end{array}$ & - Only share processed data & $\mathbf{5}$ \\
\hline Keep data offline & - Locally sharing data (USB drive, hard drives passing by hand) & $\mathbf{5}$ \\
\hline $\begin{array}{l}\text { Don't follow } \\
\text { standards or } \\
\text { conventions }\end{array}$ & $\begin{array}{l}\text { - Create new language } \\
\text { - Invent your own standard because finding out about what exists is } \\
\text { more work }\end{array}$ & $\mathbf{3}$ \\
\hline $\begin{array}{l}\text { Make data access } \\
\text { difficult or unclear }\end{array}$ & \begin{tabular}{l} 
- - - Frequent not publish metadata in a widely used data catalogue \\
\hline
\end{tabular} & $\mathbf{2}$ \\
\hline
\end{tabular}

Finally, participants were asked what the community can do - or stop doing - to achieve our desired objective of making network data useful to stakeholders outside the network. The solutions or 
behavioural changes that were suggested included: using technological solutions, to keep data online or in shared locations, or store it in a decentralized way to increase access and limit data loss. Developing carrots and sticks such as introducing incentives for people to make data open, or penalties for not doing so. This was suggested both for NSERC PermafrostNet and for tendered contracts. Making changes to institutional policies, replacing requirements of data quality with descriptions of levels of quality, or using moderation-based rather than approval-based approaches to releasing data. Finally, developing better communication would ensure that best-practices are developed with a broad group.

\section{6) Permafrost data interoperability}

\section{Priority data types for interoperability}

This workshop was focused on ground temperature data and basic geotechnical properties (such as ground ice content, and grain size) so that the scope was narrow enough to make early progress. These data types were chosen because they are currently the most widely available and are foundational to permafrost research and monitoring. However, many other data types are relevant to the permafrost community.

Participants were invited to share their priorities for which data types should be the next focus for interoperability and standardization. This was done using a ThoughtExchange survey and grouped into themes. Like other surveys in the workshop, the difference in rank between the most- and least-popular choices was relatively low $(2.9-4.1)$.

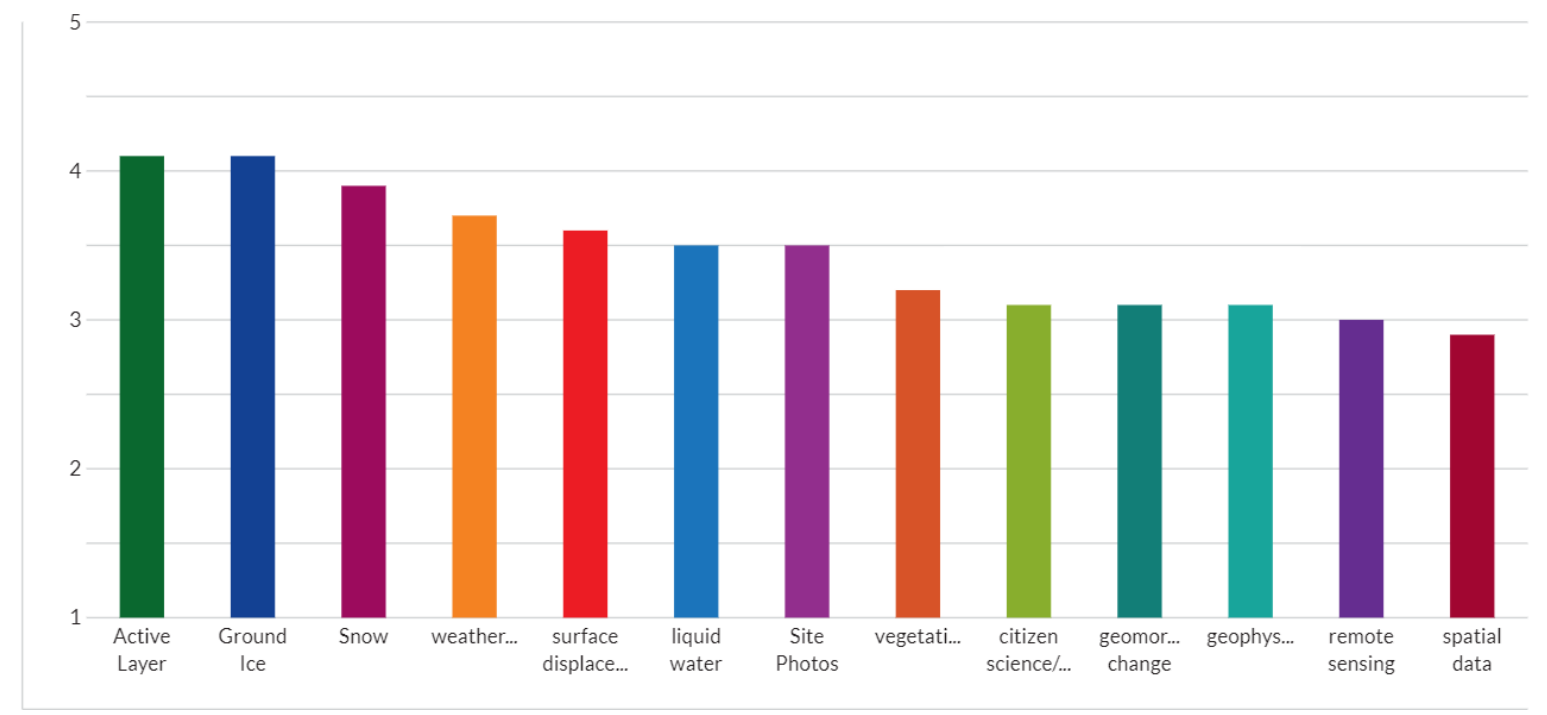

Figure 6: Participant priorities for data types to be the next focus for interoperability efforts.

This session generated a lively discussion about the best approach for identifying the next steps that should be taken, and the importance of distinguishing between established data collection or reporting conventions and data management strategies.

The polling / voting approach that was taken during the workshop was seen as important to gather broader perspectives and generate buy-in from stakeholders, but concerns were raised that a large group discussion is not appropriate for dealing with some of the technicalities. For people unfamiliar 
with using a certain kind of data, such a discussion could lead to people tuning out of an online meeting. Suggestions were made to identify a motivated group of users and experts to make a proposal for others to comment on at a future event, and to prepare it in advance with a high degree of guidance.

In future discussions of interoperability and standards, the distinction must be made between those standards governing how data are generated or collected, and the standards or specifications describing how those data are shared, or otherwise made interoperable. The development of former, which already exist in some cases (such as describing ground ice in samples), are best left to technical experts in the respective scientific domains.

\section{Vocabularies and semantics for permafrost}

The inconsistencies in the vocabulary and semantics within the permafrost community impede data sharing. Establishing a shared vocabulary and adopting it as a community is critical to data interoperability. The purpose of this session was to (1) prioritize concepts for which the network and broader permafrost community want to adopt or establish controlled vocabularies or semantics, (2) describe the process and requirements for developing this shared language, and (3) develop a shared understanding of the available resources.

The session centered around discussion among an expert panel (Table 6) who discussed the question: "What advice would you give the network to work effectively in adopting or adapting vocabularies and semantics for sharing permafrost data?". After hearing the panelist discussion, participants were given time to identify concepts for which they thought shared vocabularies would be valuable in the shortterm, then this list was given further consideration and comment from the panelists.

Table 6: Expert panellists for discussion on vocabularies and semantics

\begin{tabular}{|l|l|}
\hline Boyan Brodaric & Natural Resources Canada \\
\hline Matt Jones & Arctic Data Center, National Center for Ecological Analysis and Synthesis \\
\hline Peter Pulsifer & $\begin{array}{l}\text { Geomatics and Cartographic Research Centre, Canadian Consortium for Arctic } \\
\text { Data Interoperability }\end{array}$ \\
\hline Etienne Godin & Université Laval, Nordicana-D \\
\hline
\end{tabular}

The main recommendations from the experts were:

- Do not reinvent the wheel. Recognise previous and simultaneous efforts and engage with the broader community.

- Determine the degree of sophistication of the product (Figure 7).

- Start early to reduce effort later on.

- Split the terms from their definitions and focus on the definitions or concepts. This increases vocabulary flexibility and allows it to be multilingual.

- Permafrost experts must work together with technical experts.

- To promote engagement in the process and to reach agreement, the work on shared vocabularies needs to be done in the open. 


\title{
Semantic Continuum
}

\author{
Expressive
}

More

Expressive

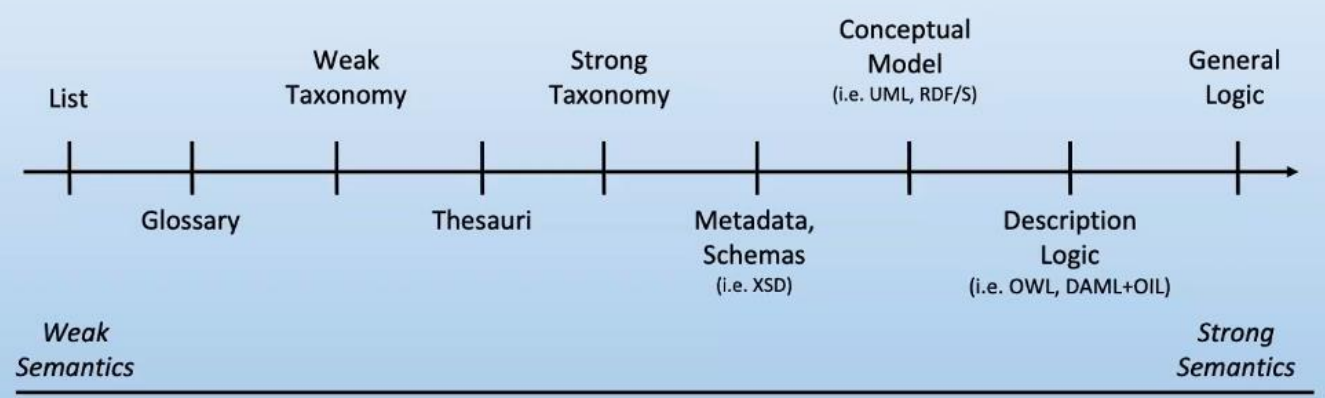

Figure 7: The semantic continuum, where the complexity and expressiveness increase from left to right (image credit: Peter Pulsifer, 20085)

Based on the discussion with the experts, the process for developing a shared vocabulary within the network or the broader permafrost research community must be iterative and involve permafrost domain experts as well as knowledge modelers and technical experts (Figure 8). There appeared to be agreement around using the Glossary of Permafrost and Related Ground-Ice Terms ${ }^{6}$ as a starting point. It was suggested that an association such as the Canadian Permafrost Association (CPA) should lead this process and that the network be used to crowd source commentary and ideas or to provide committee members. To engage with the broader international community, it was proposed we have representatives engaging in the larger process (such as the ENVO ontology).

The development of a complete permafrost ontology would represent a significant investment in effort. An agreed-upon glossary may be a more valuable and more realistic interim goal for the Canadian permafrost community as it works to make existing data more available and interoperable. However, to be efficient with resources, these efforts should be aware of existing initiatives. Several of these were mentioned in the workshop as possible collaborators that could be valuable to engage with:

- The Environment Ontology (EnvO), an international ontology designed for environmental entities such as ecosystems, environmental processes, and environmental qualities

- The Ecosystem Ontology (ECSO), a DataONE ontology originally designed for Carbon Flux measurements for MsTMIP and LTER Use Cases

- The World Wide Web Consortium (W3C) suite of ontologies

\footnotetext{
${ }^{5}$ Pulsifer, P. L. (2008). An Ontological Exploration of Antarctic Environmental Governance: Towards a Model for Geographic Information Mediation. Doctoral dissertation, Carleton University.

${ }^{6}$ http://globalcryospherewatch.org/reference/glossary_docs/permafrost_and_ground_terms_canada.pdf
} 


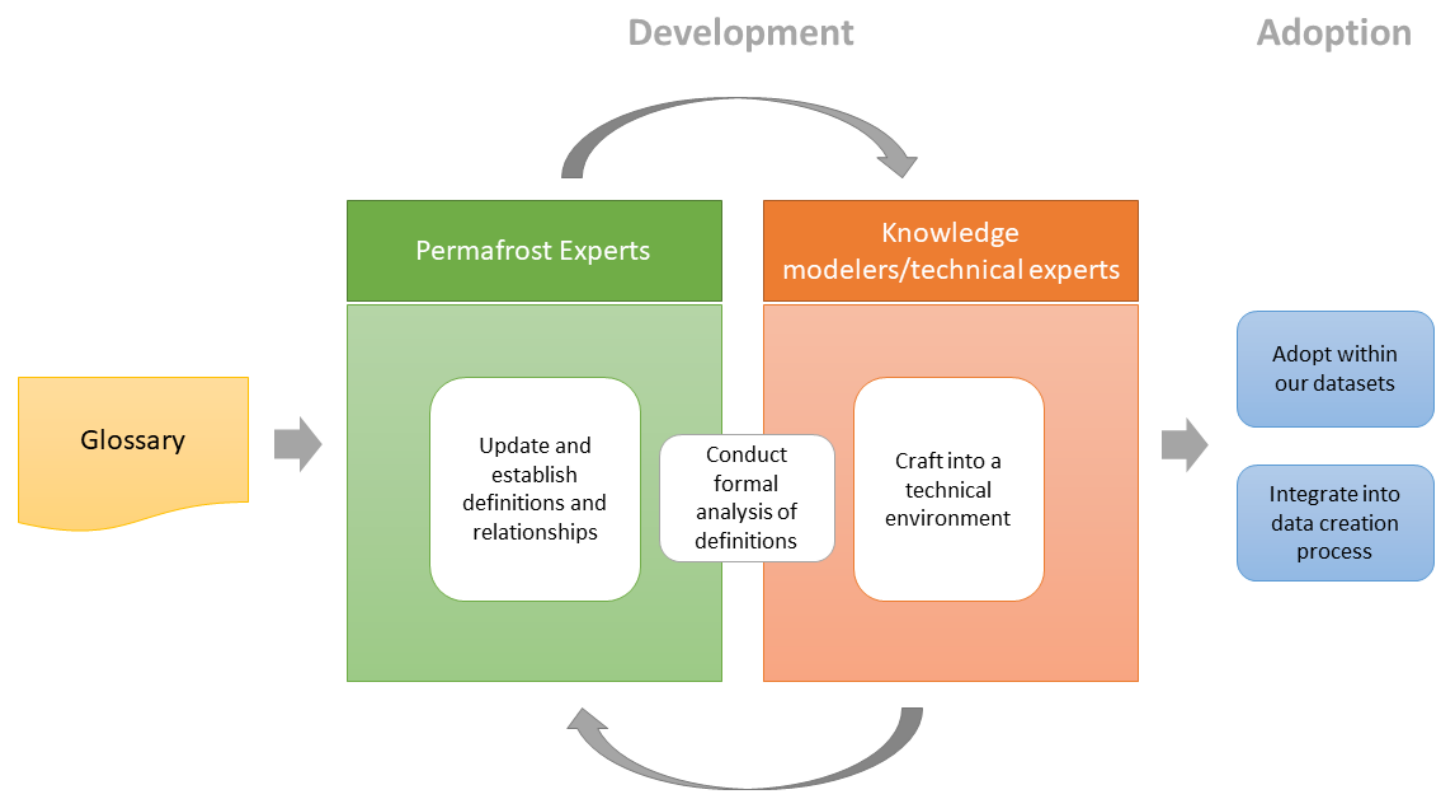

Figure 8: Process for developing a shared vocabulary within the permafrost community

Two workshop participants are engaged in efforts to improve arctic data interoperability and highlighted the importance of collaboration with existing international groups, namely:

- The Canadian Consortium for Arctic Data Interoperability (CCADI) ${ }^{7}$

- Arctic Data Committee (ADC), Vocabulary and Semantics Working Group ${ }^{8}$

- The Arctic Data Center ${ }^{9}$

\section{Standards and specifications}

Adopting shared standards and specifications will make data sharing more efficient. In this session, participants generated a list of conventions, standards, or specifications for permafrost data that they had used or encountered (Table 7). This session focused mostly on CSV-formatted data because of its ubiquity in the permafrost community.

Table 7: Existing conventions or standards for permafrost data brainstormed by participants.

\begin{tabular}{|l|l|l|}
\hline & Standards & Comments \\
\hline \multirow{5}{*}{ Time } & $\begin{array}{l}\text { Unix time, } \\
\text { Geologic time, } \\
\text { Julian Day, } \\
\text { Date and time in two separate fields, } \\
\text { YYYY-MM-DD HH:MM:SS, } \\
\text { ISO 8601 }\end{array}$ & $\begin{array}{l}\text { Radiocarbon and relative } \\
\text { dating do not fit into these } \\
\text { standards }\end{array}$ \\
\hline Time zone & $\begin{array}{l}\text { UTC, } \\
\text { Include timezone, ex: UTC-7 }\end{array}$ & \\
\hline
\end{tabular}

\footnotetext{
${ }^{7}$ https://ccadi.ca/

${ }^{8}$ https://arcticdc.org/activities/core-projects/vocabularies-and-semantics-wg

${ }^{9}$ https://arcticdata.io/
} 


\begin{tabular}{|l|l|l|}
\hline \multirow{2}{*}{ CSV structure } & $\begin{array}{l}\text { Long-format (Entity-Attribute-Value), } \\
\text { Wide-format, } \\
\text { RFC 4180 }\end{array}$ & $\begin{array}{l}\text { Format changes from data } \\
\text { collection, to processing, to } \\
\text { storage, to download }\end{array}$ \\
\hline Depth & $\begin{array}{l}\text { Meters, } \\
\text { Meters with decimals }\end{array}$ & $\begin{array}{l}\text { Is depth of borehole vertical } \\
\text { or normal to surface? }\end{array}$ \\
\hline Coordinates & $\begin{array}{l}\text { UTM coordinate system, } \\
\text { Latitude and longitude in DMS vs DD }\end{array}$ & \\
\hline Missing values & $\begin{array}{l}\text { Negatives (when it's not temperature) } \\
\text { NA, NaN, } \\
\text { Fixed values (6999, 9999, -9999) }\end{array}$ & \\
\hline Units & $\begin{array}{l}\text { Carbon content: Kg C / m } \\
\text { Temperature: Degrees Celsius } \\
\text { International System of Units (SI) }\end{array}$ & \\
\hline Variable names & CF Standard Names & \\
\hline
\end{tabular}

In a follow-up discussion, participants evaluated the merits of adopting one or more of the identified standards as a community. There were:

Time: The ISO 8601 is an unambiguous and broadly used datetime standard that participants appeared to agree should be adopted. This standard can be difficult for data entry as people prefer using two separate columns for date and time. A solution is to incorporate a translator and to adapt the standard to allow two columns.

Coordinates: Many coordinate systems were mentioned but none were agreed upon as a best-practice. The original coordinates, coordinate system and accuracy were suggested as important metadata.

Missing values: The different types of missing values need consistent codes or at least be defined in the metadata. Standards could be based on what has been already developed by the NTGS.

Ground temperature file structure: Participants agreed that both the 'wide' and 'long' format of ground temperature data are useful at different stages of data processing. A wide-to-long translator tool was suggested as a possible contribution to aid data management.

Participants also discussed developing a set of minimum metadata requirements. It was noted that these may be difficult to mandate and would be impossible to follow for legacy data. The metadata that were discussed in the session included:

- Accuracy and precision of measurements

- Classification of quality / level of processing

- Dominant vegetation

- Backfill materials

- Field photos

- Ground surface elevation

- Missing value code definitions

Participants appeared to agree that guidelines are needed to have standardized data. Although no specific consensus was reached for how this should be done, several ideas were generated:

1. Provide instruction manuals 
2. Provide 'gold standard' examples of data structure and included metadata for different data types (as done by Integrated Ocean Observing System)

3. Provide a central resource for guidelines for best practices and conventions, both in terms of data sharing and in terms of field techniques

4. Create a validation tool that checks compliance with a set of guidelines (as done by the Arctic Data Center)

\section{7) Taking Action}

\section{Summer of data}

Due to the current COVID-19 restrictions, fieldwork this summer will be significantly reduced or cancelled entirely. While unfortunate, this does create an opportunity to make significant progress on data-related activities. The purpose of this session was to scope these activities and lay out tangible next steps. Three themes were identified based on previous workshop discussion: gathering and processing legacy data, working towards a glossary in collaboration with the CPA, and liaising with Northern partners to coordinate possible data collection.

Participants chose a theme and were asked to identify what needs to be done, what support is needed or available, and as a minimum output, three actionable items that can take place within the next several months.

For the harvest of legacy data, the four stages of the work that were identified were: determining where to find the data, creating an inventory of what has been done, understanding what is needed by the data users and describing the data quality or qualities. To support this, one or more individuals are needed with an understanding of what data are out there and, in addition, personnel to do some of the hard work of gathering and cleaning it, possibly including network HQP. As next steps, participants identified: creating a sub-committee of people to take up these tasks, coming up with a strategy, and establishing a better understanding of user needs - possibly though a survey.

Updating the permafrost terms glossary has been proposed as an action group activity by the CPA. This includes the development of a glossary that can grow and develop, that integrates other permafrostrelated disciplines, and is not limited to a static pdf document. Based on discussions on day 2 of the workshop, connections in PermafrostNet were seen as a way to connect the glossary to the semantics community. To support this work, someone would need to lead the development of the glossary and integrate with semantic working groups. A postdoc was suggested as one possibility. In addition, a panel of experts to provide the scientific consensus would also be required. The next steps for this are to: identify a person or group to lead the effort and to develop a document outlining the framework of the glossary. The group of participants suggested that PermafrostNet take an active role in working with the CPA to kick off the project.

Because of restricted travel to the territories this summer, Northern network partners may be able to assist with certain field work elements that cannot be completed by those currently living in the South. For this to happen, relationships with Northern communities and organizations must be built and strengthened. The importance of long-term relationships was brought up as a way to mitigate risks to long-term environmental monitoring from large-scale events such as COVID-19. Resources must also be made available to support this work. This may include compensation, equipment, and the development 
of physically-distanced field protocols. In the short-term, participants suggested that the workshop themes be relayed to community members to let them know their input and help is valued. Fostering new partnerships and strengthening existing ones was another suggestion. Environmental monitors were identified as a possible group who could assist with this work, with the understanding that funding would be required and they would expect to return to their usual duties after the outbreak is over.

\section{Long-term strategy}

To help guide the long-term development of a permafrost data system, participants were asked to imagine themselves in 10 years using such a system, from the perspective of a someone accessing the data, someone submitting data, and as someone involved in the governance and decision making. The majority of participants cycled between breakout rooms, while one host stayed behind to take notes and synthesize ideas between groups.

From the perspective of a data user (Table 8), the imagined system is one that makes data easy to find, and accessible to experts and non-experts alike. This is achieved through providing several ways to access the data, which may include an API, an interactive interface, and a way to get detailed information about a site or dataset. In addition to the raw data, value-added products are also available. The data system is interoperable with other research domains or sources, and has rich metadata to detect duplicate datasets, or provide more information in publications.

Table 8: Elements of a permafrost data system 10 years from now, from the perspective of a data user.

\begin{tabular}{|l|l|}
\hline \multicolumn{2}{|c|}{ Accessing data } \\
\hline Interoperable & - Links to cross disciplinary impacts and other database not related to permafrost \\
& - Standards and methods to mesh datasets from different sources \\
& - Data from multiple sources accessible whichever database is used. \\
\hline Findable and & - Data are as easy to find as academic papers \\
Accessible & - Datasets easily searchable and harvestable from generic search engines \\
& - Catalogue service that offers searchable, findable metadata \\
\hline $\begin{array}{l}\text { Useable by } \\
\text { non-experts }\end{array}$ & - Online interface that doesn't require specific skills \\
\hline Multiple ways & - Interactive online for less technical users to synthesize knowledge \\
to access & - Brill down in individual data sets \\
& - Blexible use-cases \\
\hline $\begin{array}{l}\text { Provides data } \\
\text { products }\end{array}$ & - Have an API for programmatic access \\
\hline Referenced & - Interpretations of the data available \\
& - Visuals and reports for the area built in the metadata \\
\hline & - Sinks to the research papers that were published \\
\hline
\end{tabular}

From the perspective of someone adding their data to the system, (Table 9), the process of submitting data is simple and clear. They have the support of someone at the data centre to help with certain elements, and there is a division of responsibilities between the data creator and the data manager. Tools for data submission and cleaning are available. Quality control elements are split between manual and automated components. The system itself hosts historic datasets that can integrate with new data. 
The system is decentralized; the data creator may submit their data to someone locally responsible, but it will be visible in the larger system.

There were some contradictory suggestions in this session, namely about whether data should be quality checked automatically, or manually by a person, and what the balance of responsibility should be between the field scientist and data curator. On the one hand, one suggestion was that once the data are collected, all further processing should be done by the data manager. The other perspective is that the data creator is the one most familiar with the data and should therefore be the one to ensure it is properly checked and correct.

Table 9: Elements of a permafrost data system 10 years from now, from the perspective of a data creator.

\begin{tabular}{|l|l|l|}
\hline \multicolumn{1}{|l|}{\begin{tabular}{l}
\multicolumn{1}{c|}{ Submitting data } \\
submission \\
and curation
\end{tabular}} & - - Vata and metadata checkers highlight missing info, or deviation from standards \\
& - Users can upload in their own format and transformations are performed \\
& - Automatically
\end{tabular}

From the perspective of someone involved in the management or governance of the data system (Table 10), they work with a diverse group representing stakeholders from multiple sectors and user groups. The data system has a clear mandate which includes both the provision of data and the creation of summary data products. There is strong government involvement to ensure stable funding; due to the decentralized nature, this involves governments at multiple levels. The governance structure is flexible enough to respond to changes in the needs put upon it.

Table 10: Elements of a permafrost data system 10 years from now, from the perspective of someone involved in the governance body.

\section{Managing data}

Strong government involvement
- Needs long-term support and stable funding

- Academia / NSERC are not in the business of curating data 


\begin{tabular}{|l|l|}
\hline Diverse & - Representatives from user groups \\
representation & $\begin{array}{l}\text { - Take advantage of differences between sectors: academia can provide innovation } \\
\text { and nimbleness while government provides stability }\end{array}$ \\
& - Indigenous, territorial \& federal governments, academia, industry \\
\hline Clear Mandate & $\begin{array}{l}\text { - Identify gaps, find a niche, and be clear about what kinds of data are within that } \\
\text { mandate }\end{array}$ \\
& $\begin{array}{l}\text { - Requirements for engagement between organizations for use and maintenance } \\
\text { - Data curation as part of requirements }\end{array}$ \\
\hline Decentralized & - Active use of data through creation of annual summary reports, data products \\
& $\begin{array}{l}\text { - Regional structure that feeds into national and international committees } \\
\text { - Under a federal umbrella with regional management }\end{array}$ \\
\hline Flexible & - Sunding at national level for coordination between regions \\
\hline
\end{tabular}

The final part of the discussion focused on how to communicate the benefits of funding a data management system as a foundational piece for permafrost research and engineering. Discussion was focused on working towards data management as an essential part of any project or contract: currently, most permafrost data management is done using soft money through academic project funding or employees on fixed-term contracts. Because of its importance for monitoring and engineering design, the focus should be on securing more stable funding, for example through existing infrastructure development projects. In the case of large northern infrastructure projects, a relatively small fraction of this investment would significantly benefit northern capacity for permafrost data management.

Other data-providing organizations were discussed as possible models such as the Water Survey of Canada and the Canadian Integrated Ocean Observing System. Participants noted that these likely grew out of the demand for the data. Despite permafrost issues being ubiquitous in the North, governments may not yet appreciate the relevance of permafrost data.

Finally, the impact of government COVID-19 spending on the sustainability of permafrost data management was seen to present opportunities as well as challenges: There were mixed opinions on how the recent government spending would affect the long-term sustainability of any permafrost data management system that develops in the next 5 to 10 years. On the one hand, concerns were raised that research was classified a non-essential service and that funding cuts may disproportionately affect the resources that might otherwise be made available for the development of a permafrost data management system. On the other hand, continued spending on Northern infrastructure was seen as one of the ways the government may mitigate a possible recession because it remains a key driver of the economy. The case for better funding for permafrost data management is only strengthened by increased infrastructure spending and climate change.

There was some divergence of opinions on how this uncertainty should be handled. One proposed solution was to rely as much as possible on existing international data systems to ensure long-term stability and minimize risk. Other participants felt that interfacing with and benefiting from other international efforts was important, but that Canada has significant needs for which it should not rely on others providing the services. 


\section{Motivating progress:}

On the last day, a group of participants set out to answer the question: "How do we motivate individuals or teams to take on the often large and unrewarding task of uploading current and historical data?". The group self-organized to come up with a framework, laying out steps to take in the short- and long-term. Motivation was seen to occur at two levels: at the strategic level where direction is established and at the operational level where work gets done.

The ideas discussed for motivating proper data management and data sharing can be summarised into five themes: (1) Resources, which are needed to make things possible; (2) Recognition of those involved in each step of the data creation tasks. This can be achieved through references, and at the network level through an annual database report which highlights top data contributors. Keeping track of data usage and having data users provide feedback can also be motivating; (3) Communication with and among those completing the data management tasks is very important to motivate at the operational level. Annual workshops would facilitate sharing methods and challenges and highlighting the outcomes and final products. A working group of people involved in data management could promote continuous communication between annual events; (4) A governance structure, with a leader to mobilize people, and a committee with a cross-section of stakeholders. With leadership and clear objectives, operational measures are implemented that align with the long-term data management strategies. (5) The adoption of policies or regulations, with requirements to incorporate data management into projects or to upload data in a standardized format and within a certain time frame of collection. Territorial Governments have already started writing these requirements into their contracts.

Table 11: Participant comments on how to motivate progress for data-related activities

\begin{tabular}{|c|c|c|c|}
\hline & Next steps & Short-term & Long-term \\
\hline $\begin{array}{l}\text { Secure } \\
\text { Resources }\end{array}$ & $\begin{array}{l}\text { - Identify what } \\
\text { resources are } \\
\text { required (and } \\
\text { available!) }\end{array}$ & $\begin{array}{l}\text { Develop common automated } \\
\text { methods with documentation }\end{array}$ & $\begin{array}{l}\text { - Stable funding for } \\
\text { sustainability }\end{array}$ \\
\hline $\begin{array}{l}\text { Create } \\
\text { governance \& } \\
\text { leadership }\end{array}$ & 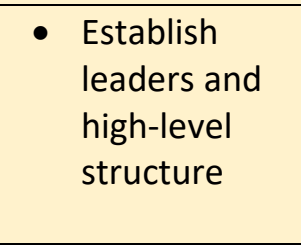 & $\begin{array}{l}\text { - Create working groups with } \\
\text { regular meetings to share } \\
\text { experience } \\
\text { - Increase capacity for legacy } \\
\text { data }\end{array}$ & $\begin{array}{l}\text { - Need a strong strategic } \\
\text { leader or champion }\end{array}$ \\
\hline $\begin{array}{l}\text { Give } \\
\text { recognition }\end{array}$ & & $\begin{array}{l}\text { - Recognize people doing the } \\
\text { work } \\
\text { - Track data usage, so we can see } \\
\text { that our efforts are being put } \\
\text { to good use } \\
\text { - Demonstrate the final products } \\
\text { so people can see what they } \\
\text { are contributing to }\end{array}$ & \\
\hline
\end{tabular}




\begin{tabular}{|c|c|c|}
\hline Communicate & $\begin{array}{l}\text { - Involve the private sector (this } \\
\text { may require additional } \\
\text { resources) } \\
\text { - Unify the fragmented data } \\
\text { landscape, including within the } \\
\text { public sector }\end{array}$ & $\begin{array}{l}\text { - Annual workshop to talk } \\
\text { about what data you are } \\
\text { looking for to incentivise } \\
\text { collaboration and } \\
\text { efficiency in data } \\
\text { collection. } \\
\text { - Develop connections } \\
\text { between data collectors, } \\
\text { data entry and end } \\
\text { users }\end{array}$ \\
\hline $\begin{array}{l}\text { Change } \\
\text { regulation \& } \\
\text { policies }\end{array}$ & $\begin{array}{l}\text { - Create accountability through } \\
\text { data management plans in new } \\
\text { project proposals }\end{array}$ & $\begin{array}{l}\text { - Regulatory or contract } \\
\text { requirements for data } \\
\text { submission }\end{array}$ \\
\hline
\end{tabular}

\section{8) Final thoughts and next steps}

The outputs of this workshop point to a need for continued collaboration and communication at all steps of the data creation process. NSERC PermafrostNet is currently organizing semi-regular meetings for those involved in developing permafrost data systems in Canada. These will continue to help ensure data systems do not develop in isolation, and to strengthen the Canadian permafrost data community of practice. Increasing involvement from the private sector is a priority to diversify representation and also help advocate for the need for better permafrost data management as a part of new projects or contracts. The next planned formal opportunities to discuss permafrost data will be at an online session as part of the NSERC PermafrostNet AGM in November 2020, and at the permafrost data systems workshop session at the Regional Conference on Permafrost (RCOP) in Boulder, Colorado in July $2021^{10}$.

Some of the issues brought up during the workshop highlighted how field data collection methods can impact the ease with which data can be shared and disseminated. Although these issues were out of scope for this workshop, NSERC PermafrostNet had planned a fieldwork rehearsal to harmonize and share data collection methodologies which could have been a forum to discuss some of them. This event was scheduled to be held in the days leading up to the data workshop, and the two events were intended to complement one another. A similar event in the future, possibly combined with a smaller discussion on data management, may offer an opportunity to revisit this area of overlap.

Going forward, the next steps for NSERC PermafrostNet will include releasing version 1 of the network data policy, and developing a white paper outlining a vision for permafrost data in Canada, based in part on the outcomes of this workshop. The network will also continue to prototype integrated permafrost data management and shared governance. The network provides a forum that is fundamental for data stewardship and decision making so that researchers can focus on research. By connecting permafrost data management expertise (GSC, YGS, NTGS and elsewhere), a system can be developed that is interoperable and sustainable. For more information, or to get involved, contact Nick Brown (nick.brown@carleton.ca) the Permafrost Data Scientist of NSERC PermafrostNet or visit the PermafrostNet website (permafrostnet.ca/data).

10 https://www.uspermafrost.org/21rcop/sessions.shtml 


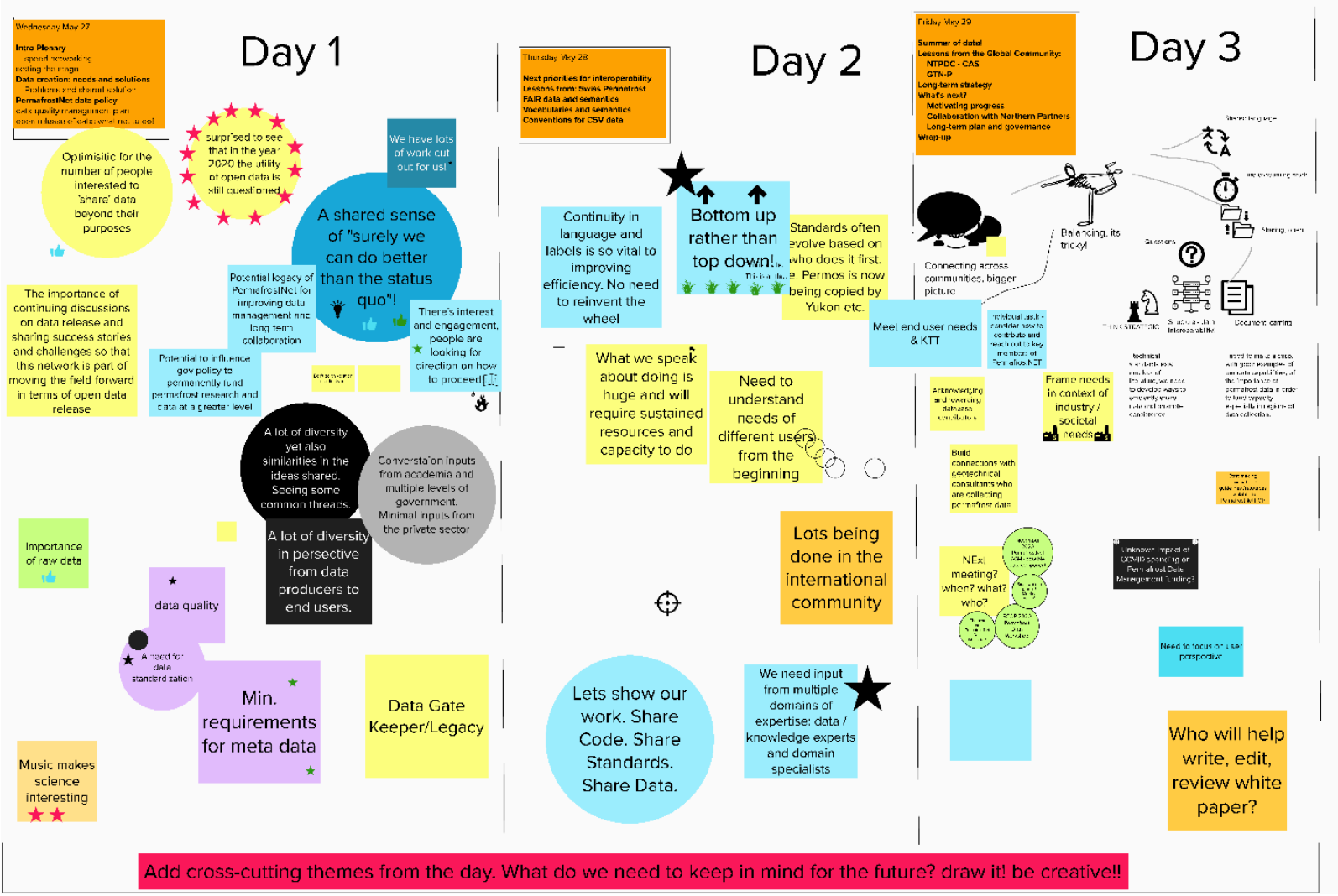

Figure 9: At the end of each day, participants were asked to jot down ideas or cross-cutting themes on a Mural board that synthesized the results from the day. A full-resolution version of this board is provided inAppendix IV. 


\section{9) Appendices}

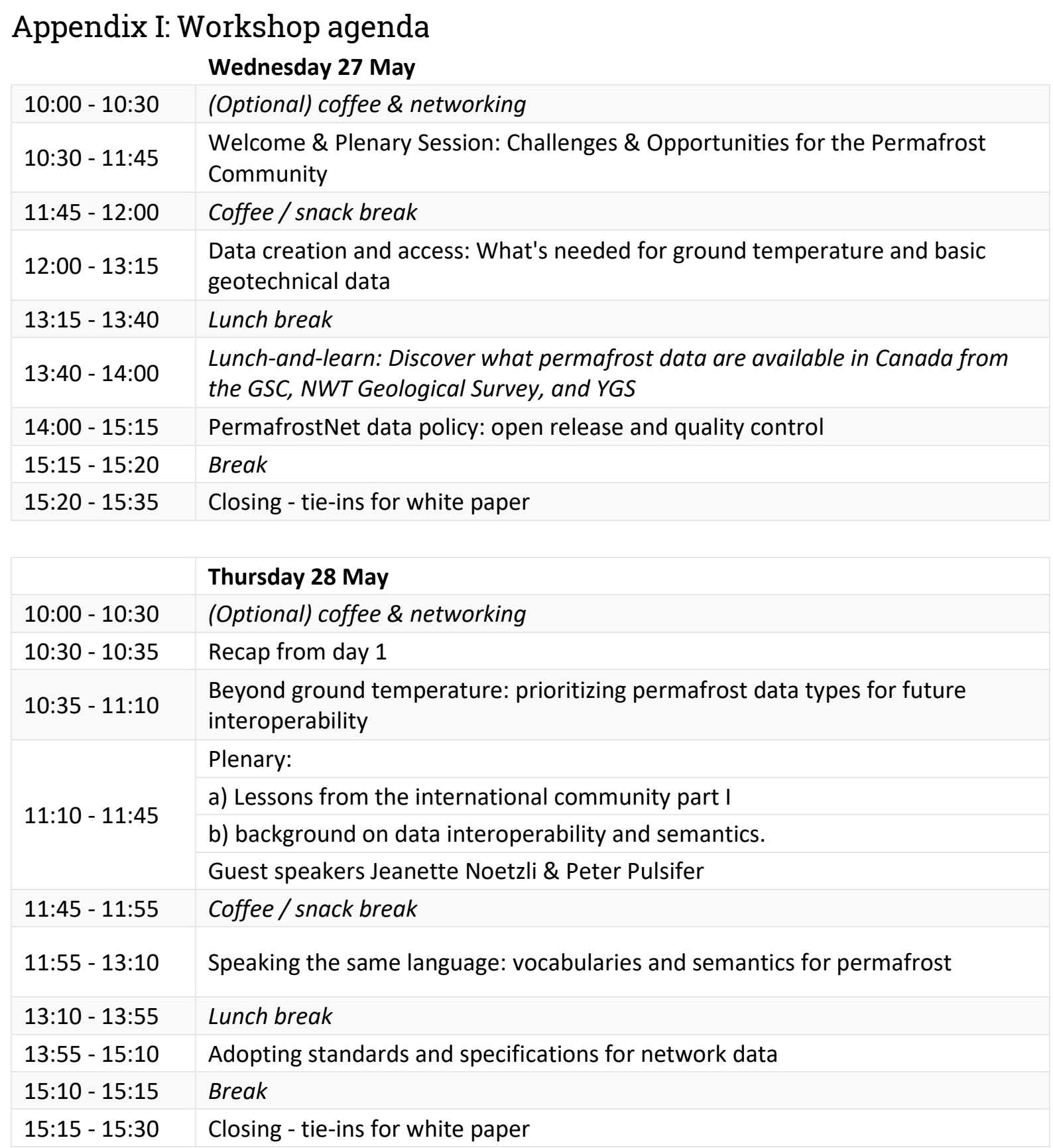

\section{Friday 29 May}

10:00 - 10:30 (Optional) coffee \& networking

10:30 - 10:35 Recap from day 2

10:35 - 11:10 Summer of data: how to make the best of the field season during a pandemic 

$11: 10-11: 40$
Plenary: Lessons from the international community part II.
$11: 40-11: 55$
Guest speakers Xiaoduo Pan \& Dmitry Streletskiy
$11: 55-13: 10$
Coffee / snack break
$13: 10-13: 55$
$13: 55-14: 55$
Long-term strategy: what is needed for permafrost data in Canada?
Lunch break
Your priorities: what needs more discussion? ( 3 time slots available, topics to be
$14: 55-15: 00$ determined)
$15: 00-15: 30$
Break
Closing - next steps

\section{Appendix II: Participant list}

\begin{tabular}{|c|c|c|}
\hline Name & Location & Organization \\
\hline Tristan MacLean & Ottawa, ON & PermafrostNet \\
\hline Nick Brown & Ottawa, ON & PermafrostNet \\
\hline Shirley McKey & Ottawa, ON & PermafrostNet \\
\hline Anne Barker & Ottawa, ON & National Research Council \\
\hline Alex Gao & Ottawa, ON & PermafrostNet \\
\hline Michel Paquette & Kingston, ON & Queen's University \\
\hline Emma Stockton & Ottawa, ON & PermafrostNet \\
\hline Danielle Chiasson & Churchill, MB & Churchill Northern Studies Centre \\
\hline Hannah Macdonell & Ottawa, ON & Carleton University \\
\hline Catherine Kim & Ottawa, ON & Transport Canada \\
\hline Alex Bevington & Prince George, BC & BC Government \\
\hline Moya Painter & Yellowknife, NT & NWT Geological Survey \\
\hline Stephan Gruber & Ottawa, ON & Carleton University \\
\hline Jenna Craig & Ottawa, ON & Transport Canada \\
\hline Michelle Blade & Iqaluit, NU & Canada-Nunavut Geoscience Office \\
\hline Igor Egorov & Ottawa, ON & National Research Council \\
\hline Dawn Rybchynski & Yellowknife, NT & Government of the NWT \\
\hline Ashley Rudy & Yellowknife, NT & NWT Geological Survey \\
\hline Dima Streletskiy & Washington & George Washington University \\
\hline Pascale Roy-Leveillee & Sudbury, ON & Laurentian University \\
\hline Michelle Laurie & Rossland, BC & PermafrostNet \\
\hline Sharon Smith & Ottawa, ON & Geological Survey of Canada \\
\hline Jocelyn Hayley & Calgary, AB & University of Calgary \\
\hline Samuel Gagnon & Montreal, QC & Université de Montréal \\
\hline David Arthurs & Ottawa, ON & PolarView \\
\hline Tim Ensom & Yellowknife, NT & Wilfred Laurier University \\
\hline Zakieh Mohammadi & Calgary, AB & University of Calgary \\
\hline
\end{tabular}




\begin{tabular}{|c|c|c|}
\hline MohammadHossein Gamshadzaei & Montreal, QC & Université de Montréal \\
\hline Linda Ham & Iqaluit, NU & Canada-Nunavut Geoscience Office \\
\hline Brendan O'Neill & Ottawa, ON & Geological Survey of Canada \\
\hline Alice Wilson & Inuvik, NT & Government of the NWT \\
\hline Sara Brown & Yellowknife, NT & NWT Association of Communities \\
\hline Daniel Fortier & Montreal, QC & Université de Montréal \\
\hline Joe Melton & Victoria, BC & Environment and Climate Change Canada \\
\hline Panya Lipovsky & Whitehorse, YT & Yukon Geological Survey \\
\hline Adam Kirkwood & Sudbury, ON & Laurentian University \\
\hline Jonas Darey & Montreal, QC & Université de Montréal \\
\hline Sarah Gauthier & Quebec, QC & Université Laval \\
\hline Bingqian Zhang & Vancouver, BC & Simon Fraser University \\
\hline Emilie SJ & Whitehorse, YT & Carleton University \\
\hline Christina Béland & Iqaluit, NU & Qaujigiartiit health research centre \\
\hline Patrick Jardine & Ottawa, ON & Carleton University \\
\hline Shawn Kenny & Ottawa, ON & Carleton University \\
\hline Brian Sieben & Ottawa, ON & Environment and Climate Change Canada \\
\hline Kate Swan & Ottawa, ON & Carleton University \\
\hline Eva Thévenin & Montreal, QC & Université de Montréal \\
\hline Miki Ehrlich & Yellowknife, NT & NWT Association of Communities \\
\hline Matt Jones & Santa Barbra & Arctic Data Center \\
\hline Christopher Burn & Ottawa, ON & Carleton University \\
\hline Bin Cao & Beijing & Chinese Academy of Sciences \\
\hline Kala Pendakur & Ottawa, ON & Standards Council of Canada \\
\hline Cameron Ross & Kingston, ON & Royal Military College \\
\hline Jeannette Nötzli & Davos & PERMOS \\
\hline Fereshteh Ghiami Shomami & Gifu, Japan & Gifu University \\
\hline \multicolumn{3}{|l|}{ Federico } \\
\hline Elisabeth Hardy-Lachance & Montreal, QC & Université de Montréal \\
\hline Xiaoduo Pan & Beijing, China & Chinese Academy of Sciences \\
\hline Brett Elliot & Whitehorse, YT & Yukon Geological Survey \\
\hline Antoni Lewkowicz & Ottawa, ON & University of Ottawa \\
\hline Kate Grandmont & Montreal, QC & Université de Montréal \\
\hline Peter Pulsifer & Ottawa, ON & Carleton University \\
\hline Jarrod Haas & Vancouver, BC & Simon Fraser University \\
\hline Jan Beutel & Zurich, Switzerland & ETH Zurich \\
\hline Maribeth Murray & Calgary, $A B$ & CCADI, University of Calgary \\
\hline Alessandra Kempson & Sudbury, ON & Laurentian University \\
\hline Kati Laakso & Edmonton, $A B$ & University of Alberta \\
\hline
\end{tabular}




\begin{tabular}{|l|l|l|}
\hline Ravi Darwin Sankar & Calgary, AB & CCADI \\
\hline Danika Ouellette & Calgary, AB & University of Calgary \\
\hline Boyan Brodaric & Ottawa, ON & Natural Resources Canada \\
\hline Beth Cowan & Yellowknife, NT & Government of the NWT \\
\hline Logan Rudkevitch & Yellowknife, NT & Government of the NWT \\
\hline Manny Kudlak & Sachs Harbour, NT & Inuvialuit Game Council \\
\hline Etienne Godin & Quebec, QC & Université Laval \\
\hline Srini Sundaram & & \\
\hline LeeAnn Fishback & Churchill, MB & Churchill Northern Studies Centre \\
\hline CORIS & Ottawa, ON & Carleton University \\
\hline Steve Kokelj & Yellowknife, NT & NWT Geological Survey \\
\hline Lin Chen & Quebec, QC & Université Laval \\
\hline
\end{tabular}




\section{Appendix III: Participation throughout the day}

The level of attendance throughout the day was obtained from the zoom records. After cleaning the data to account for participants renaming themselves, the total level of attendance was plotted. Participants were classified based on their affiliation to the network and based on their location (Northern Canada, Southern Canada and International)
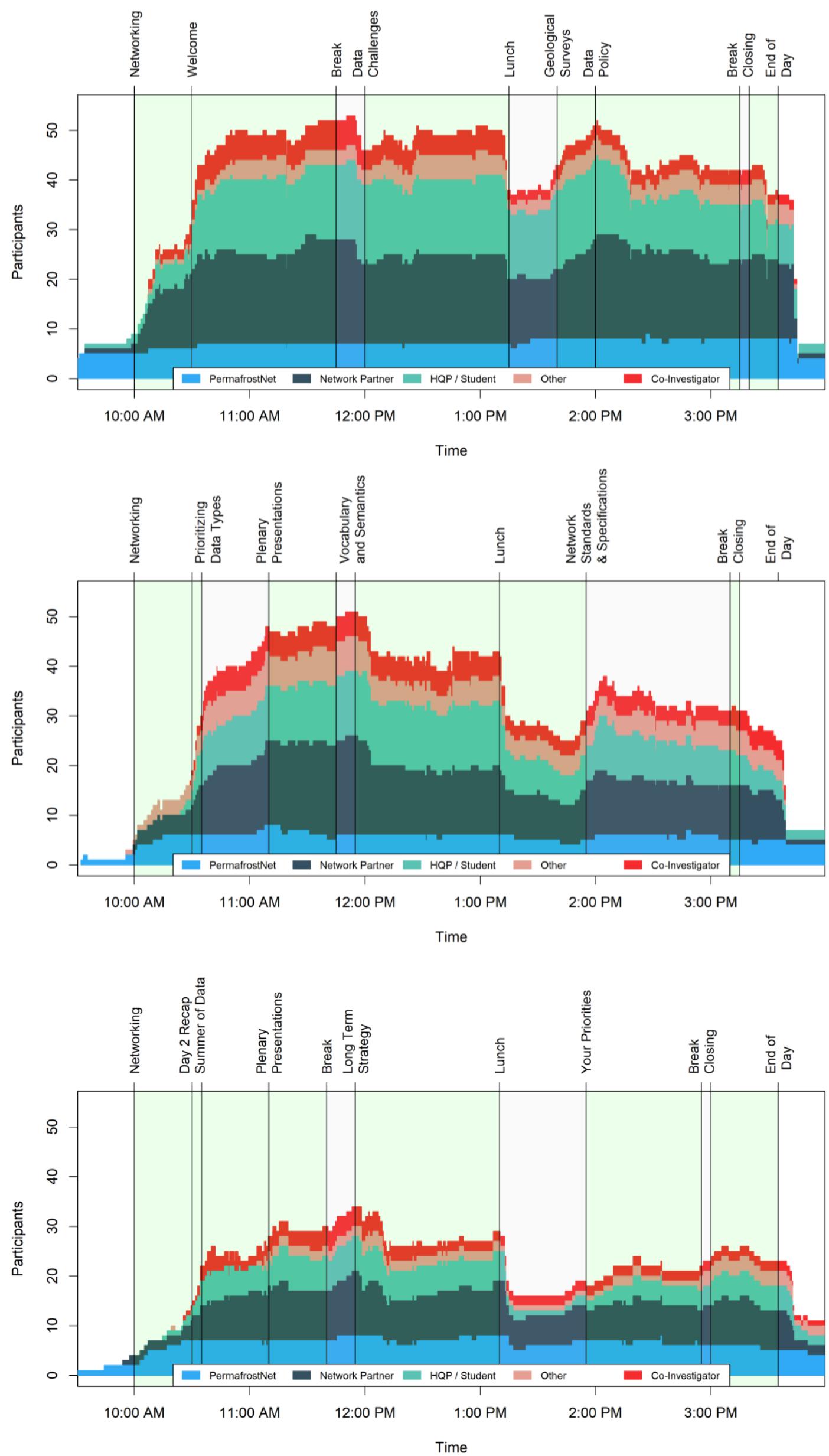

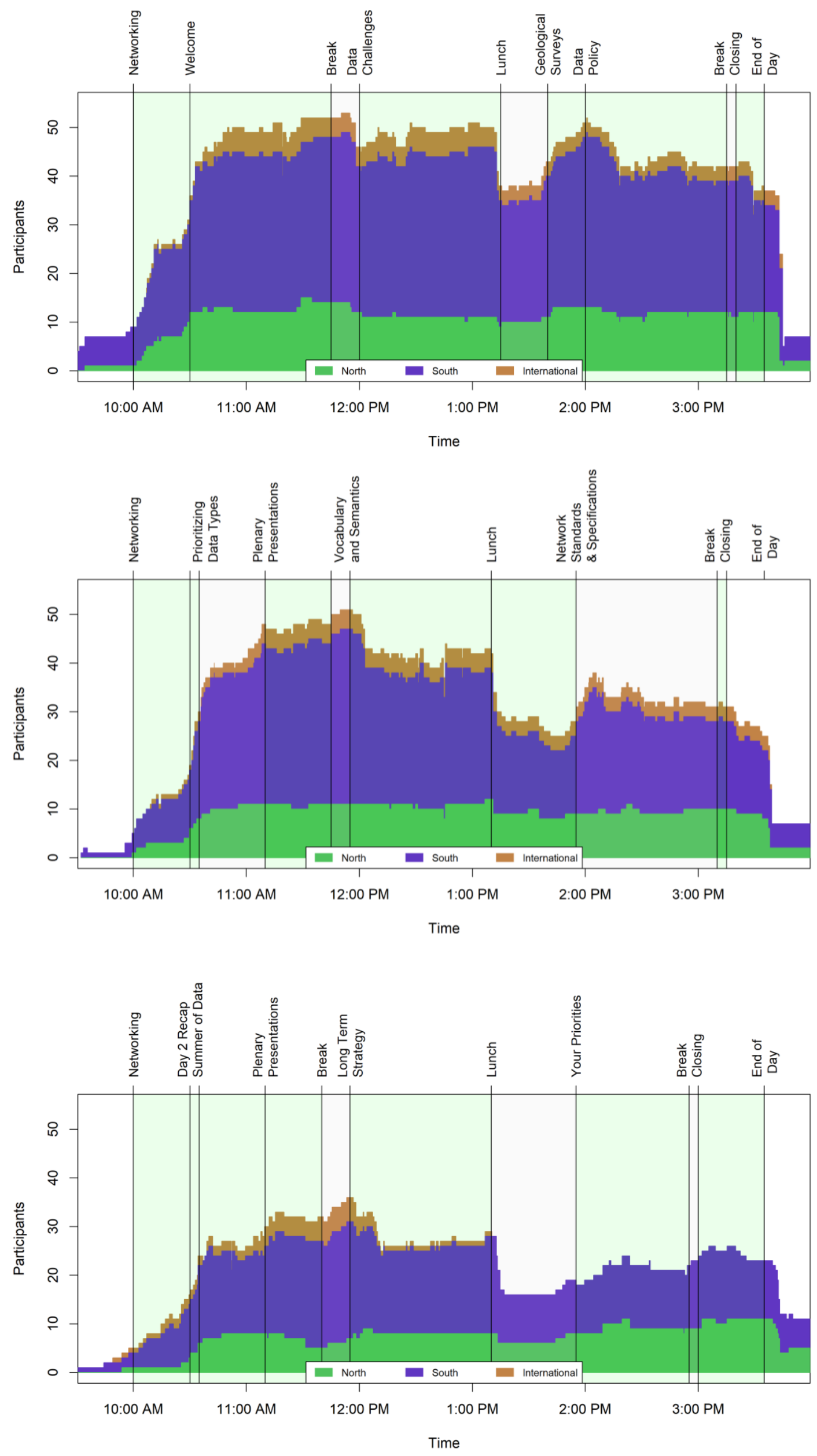
Appendix IV: Mural boards 


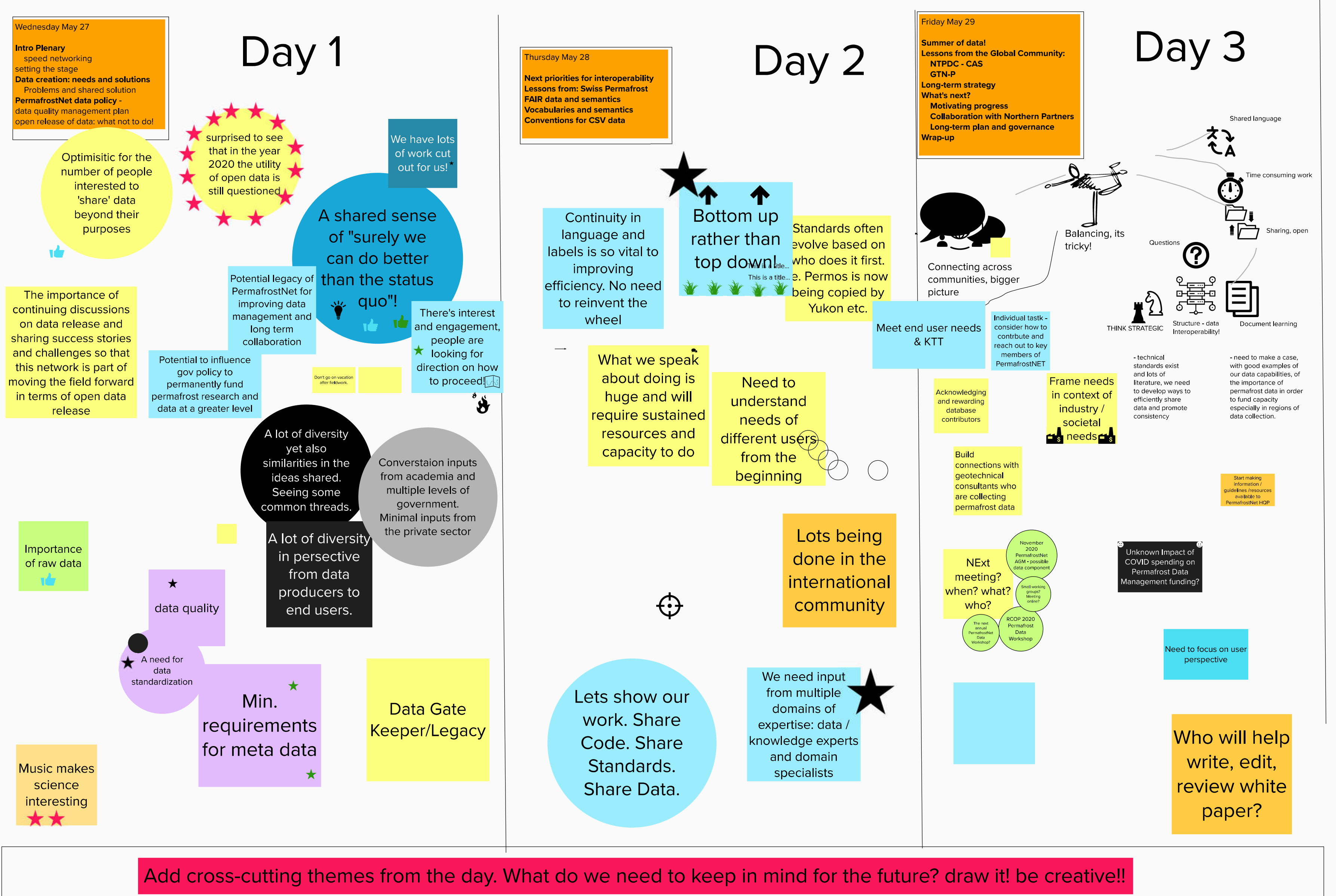

